\title{
La contratación de entidades y organismos del sector público no considerados Administraciones públicas
}

\author{
Francisca Villalba Pérez \\ Profesora Titular de Derecho Administrativo \\ Universidad de Granada
}

Sumario: I. CUESTIONES PRELIMINARES. 1.1. Resistencia del legislador a someter la contratación de entidades distintas a las Administraciones públicas a una normativa determinada y estable. 1.2. Evolución normativa como consecuencia de la jurisprudencia comunitaria.-II. LA CONTRATACIÓN DE LOS ENTES INSTRUMENTALES EN LA LEY DE CONTRATOS DEL SECTOR PÚBLICO. 2.1. Ámbito subjetivo de aplicación. 2.2 Tipología contractual. 2.3 Jurisdicción competente.-III. DISPOSICIONES GENERALES SOBRE LA CONTRATACIÓN DEL SECTOR PÚBLICO.-IV. PARTES, OBJETO, PRECIO Y GARANTÍAS PARA CONTRATAR.-V. PREPARACIÓN Y ADJUDICACIÓN DEL CONTRATO POR PODERES ADJUDICADORES.-VI. ADJUDICACIÓN DEL CONTRATO POR OTROS SUJETOS DELSECTOR PÚBLICO.VII. BREVE REFERENCIA A LOS PRINCIPIOS GENERALES DE LA CONTRATACIÓN PÚBLICA.

\section{CUESTIONES PRELIMINARES}

\subsection{Resistencia del legislador a someter la contratación de entidades distintas a las Administraciones públicas a una normativa determinada y estable}

No es nueva la resistencia del legislador a que la contratación de las entidades y organismos públicos no considerados Administración pública' cuente con una regulación determinada, precisa, y estable. Deberá ser ágil y flexible como consecuencia de su específico régimen jurídico-privado, pero no exenta de la objetividad y transparencia que exige el manejo de fondos públicos e impone el ejercicio de actividades de

$1 \quad$ Nos referimos a las entidades públicas empresariales y organismos asimilados dependientes de las Comunidades Autónomas, sociedades mercantiles públicas y fundaciones del sector público. 
carácter público². Sin embargo, el historial normativo de este ámbito demuestra que no siempre se ha considerado así. Veámoslo.

Los procedimientos contractuales de la Administración se regulan por primera vez en nuestro Derecho con carácter general en 1852 a través del Real Decreto de Bravo Murillo de 27 de febrero, que obligó a la Administración a someterse a procedimientos reglados en la selección de contratistas. Posteriormente, la Ley de Administración y Contabilidad de 1 de julio de 1911 incorpora en su articulado la normativa contractual de la Administración ${ }^{3}$ hasta su específica regulación por la Ley de Contratos del Estado de 1965 (LCE) ${ }^{4}$, que tuvo un inicial desarrollo mediante el Reglamento de Contratos del Estado de 1967 (RCE), modificado posteriormente como consecuencia de la reforma legislativa aprobada en 1973. El Reglamento de 1967 intentó ofrecer algunas pautas contractuales de naturaleza pública a la preparación y adjudicación de los contratos celebrados por las empresas nacionales ${ }^{5}$ y los entes públicos sujetos al Derecho privado, «obligándoles» a elaborar pliegos de cláusulas adaptados a sus peculiaridades empresariales (artículo 398) ${ }^{6}$. El tenor literal del precepto reglamentario

2 No debemos olvidar que la Administración, sea cual sea su forma de personificación, ha de sujetarse a una serie de principios establecidos en la propia Constitución, y el ordenamiento jurídico comunitario exige garantizar la transparencia de la contratación del sector público como medio para lograr la objetividad de la actuación administrativa y el respeto a los principios de igualdad, no discriminación y libre concurrencia. El gasto público que conlleva la contratación del sector público ha de realizarse siguiendo los principios y garantías constitucionales y con criterios de buena administración, objetividad, imparcialidad y servicio a los intereses generales. Por ello, la interpretación de los preceptos contractuales de todo el sector público no podrá suponer un escape o disminución de principios y garantías constitucionales.

3 El Capítulo V de la Ley de Administración y Contabilidad de 1 de julio de 1911, dedicado a la regulación de los sistemas de selección del contratista, incluía también normas sobre la capacidad del contratista, los controles administrativos y el privilegio de decisión de oficio. Sobre la evolución normativa de la contratación pública véanse Parada Vázquez, R. (1965), «La nueva Ley de Contratos del Estado», Revista de Administración Pública, 47: 399; Bustillo Bolado, R. (2001), Convenios y contratos administrativos: transacción, arbitraje y terminación convencional del procedimiento, Navarra: Aranzadi, pp. 121 a 163 ; Del Saz Cordero, S. (1993), «Los contratos de la Administración y el Derecho comunitario», en la obra colectiva El desenvolupament del Dret Administratiu europeu, Barcelona: Escola d'Administració Pública de Catalunya, p. 230; Bassols Coma, M. (1995), «Evolución sobre contratación administrativa», en VV.AA. Derecho de los contratos públicos, Barcelona: Praxis, pp. 30 y siguientes.

4 Existía en aquella época una total concordancia entre personalidad jurídica y régimen jurídico aplicable, sólo roto en contadísimas ocasiones. De forma que si se trataba de entes territoriales o de entes instrumentales con personificación pública, se regían íntegramente por el Derecho administrativo, incluida la contratación. Por el contrario, las sociedades mercantiles de capital íntegramente público creadas para realizar actividades industriales y comerciales, se regían en su totalidad por el Derecho privado y, en consecuencia, también su actividad contractual. Vid. Del Saz Cordero, S. (2007), «La nueva Ley de Contratos del Sector Público ¿un nuevo traje con las mismas rayas?» Revista de Administración Pública, 174: 352.

5 Terminología utilizada por la Ley de Entidades Estatales Autónomas de 26 de diciembre de 1958 (LEEA) para referirse a determinadas entidades y organismos instrumentales.

6 Especificaba el mencionado precepto que las empresas nacionales y los entes públicos que se rigen por el Derecho privado en sus relaciones con terceros deberán preparar y adjudicar su contratos de obras y suministro conforme a la legislación de contratos del Estado, salvo que sus normas constitutivas lo prohíban o la naturaleza del tráfico que realizan sea de todo punto incompatible con las reglas de aquéllas. A estos efectos, deberán elaborar pliegos de cláusulas adaptando las reglas de la legislación presente al carácter que ostentan las referidas empresas y entidades con las peculiaridades de su funcionamiento 40 (artículo 398 del Reglamento de la Ley de Contratos del Estado de 1967). 
supuso una auténtica innovación pues hasta entonces la actividad contractual de la mayoría de las empresas públicas había quedado fuera del ámbito de aplicación de la contratación pública.

Las reacciones contrarias al sometimiento de las empresas nacionales al artículo 398 del RCE no se hicieron esperar, argumentando, en algunos casos, la contradicción legal existente entre el precepto reglamentario y el artículo 91 de la LEEA7, y en otros, que la naturaleza jurídico-privada de las citadas empresas les impedía someterse a normas públicas ${ }^{8}$. El Consejo de Estado emitió el 9 de mayo de 1968 un Dictamen afirmando que los contratos de las empresas nacionales no podían quedar sometidos al cuerpo normativo de la LCE por la evidente incompatibilidad entre normas públicas y normas privadas sobre contratación`. La Dirección General de lo Contencioso del Estado y la Dirección General de Patrimonio consideraron también al artículo 398 del RCE como una reglamentación interna de carácter doméstico, sin trascendencia para las relaciones contractuales con terceros, no pudiéndose invocar derecho alguno frente a las empresas públicas que lo incumplieran.

Por último, el 11 de julio de 1968 el Consejo de Estado elevó una Moción al Gobierno solicitando la derogación del artículo 398 del RCE ${ }^{10}$, y el problema se resolvió derogando el mencionado precepto y sustituyéndolo por la disposición transitoria $2 .^{\text {a }}$ del

7 Establecía el artículo 91 de la LEEA que las sociedades mercantiles en cuyo capital sea mayoritaria la participación, directa o indirecta, de la Administración del Estado o de sus organismos autónomos, y demás entidades estatales de Derecho público, se regirán por las normas de Derecho mercantil, civil y laboral.

8 Véase el comentario sobre la polémica suscitada entre la Intervención General del Estado y la Empresa Nacional Bazán S.A, a raíz de la aplicación del mencionado precepto reglamentario de Pérez Moreno, A. (1996), «La contratación de entes instrumentales: sociedades mercantiles y demás entidades del sector público", en Comentarios a la Ley de Contratos de las Administraciones Públicas, obra colectiva dirigida por Gómez Ferrer, Morant, Madrid: Cívitas, pp. 856 y ss.

9 El Dictamen del Consejo de Estado -fruto de la consulta formulada por el Ministerio de la Marina sobre la prevalencia del artículo 91 de la LEEA frente al artículo 398 del RCE de 1967- señalaba que la contratación privada, dentro de la cual se mueven las empresas nacionales, está dominada por el principio de autonomía de la voluntad, que se manifiesta entre otros aspectos, en la elección de la otra parte contratante y en la libre elaboración del contenido negocial (Recopilación de Doctrina Legal, Dictamen número 126, expediente 35911, 1971).

10 Insiste el Consejo de Estado que la naturaleza de las sociedades conlleva inexorablemente la aplicación de reglas contractuales de Derecho privado, excluyendo de ese modo la posibilidad de que se apliquen las reglas de la contratación administrativa. Añadiendo que la seguridad jurídica que para los terceros contratistas significa la aplicación de un ordenamiento, que es también el mismo al que dichos terceros están sometidos, se vería fuertemente perturbada si los contratos de las empresas nacionales pudieran ser anulados por vicios de procedimiento, al no haber observado, en la fase de formación de la voluntad, o en la selección de la otra parte contratante, las estrictas reglas de la contratación administrativa. Vid., Ariño Ortiz, G. (1981), «La empresa pública», en El modelo económico en la Constitución española, obra colectiva dirigida por Garrido Falla, F., Madrid, pp. 190-192; Rivero Isern E. (1980), «Los contratos de las empresas públicas estatales», en Empresa pública española, Madrid: IEF y Ministerio de Hacienda, p. 365; Jiménez de Cisneros, F.J. (1987), Los organismos autónomos en el Derecho español: tipología y régimen jurídico, Madrid: INAP, p. 375; López de Castro (1994), ¿Privatizar el Estado? Madrid: Fundación BBV, p. 66; Martínez López-Muñiz, J.L. (1998), «Examen de los contratos de los entes instrumentales. Estudio especial del Derecho comunitario", en Eficacia, discrecionalidad y control judicial, Madrid: Cuadernos de Derecho Judicial, CGPJ, p. 356. 
Reglamento General de Contratos del Estado, aprobado por Decreto 3410/1975, de 25 de noviembre (RGCE), después de la reforma legislativa producida en la Ley de Contratos en 1973.

La nueva regulación contractual de los entes instrumentales sujetos al Derecho privado contenida en la disposición transitoria $2 .{ }^{a}$ del RGCE de 1975, flexibilizó el rigor del artículo 398 del RCE de 1967. Del mandato imperativo del artículo 398 «deberán respetar», la disposición transitoria $2 .^{\text {a }}$ del RGCE incorpora la expresión «procurarán respetar en su actuación», que corresponderá supervisar su cumplimiento a los consejos de administración, para lo que se les concede un amplio margen de libertad en la interpretación de las dudas que suscite su aplicación e incluso su adaptación a las peculiaridades de la empresa o entidad. La nueva regulación abre la posibilidad de dictar normas especiales sometidas al régimen jurídico de la empresa pública. En defecto de esta normativa específica, se aplicarían los principios de la LCE ${ }^{11}$, salvo que la naturaleza de la actividad fuese incompatible con aquéllos.

Aunque el precepto reglamentario aportó un interesante marco normativo publificado para la contratación de los entes del sector público sujetos al Derecho privado ${ }^{12}$, la formulación de su enunciado: «procurarán respetar», y la ausencia de vías para exigir su efectivo cumplimiento, convirtieron, en muchos casos, la disposición transitoria 2. ${ }^{a}$ del RGCE en una recomendación con efectos exclusivamente internos. Sus repercusiones jurídicas no fueron especialmente intensas debido a la flexibilidad de interpretación que sobre su aplicación se les reconoció a los gestores de las sociedades públicas. También influyó la consideración doctrinal'13 de esa época de que la actividad contractual de

11 Principios, que no normas.

12 La disposición transitoria segunda del RGCE establecía que las empresas nacionales, las entidades participadas mayoritariamente por el Estado, y los entes públicos sujetos al derecho privado en sus relaciones con terceros se sujetarán en materia de contratación de obras y suministros a sus normas administrativas especiales, y a las que puedan dictarse sobre régimen jurídico de la empresa pública, aplicándose en su defecto los principios de la presente legislación, salvo que la naturaleza de la operación a realizar sea incompatible con aquéllos. En particular, procurarán respetar en su actuación contractual al objeto de conseguir un comportamiento homogéneo en todo el sector público, los siguientes principios:

a) Rigurosa preparación de los proyectos, especificaciones y pliegos de condiciones;

b) La celebración de los contratos respetando, como regla general, los principios de publicidad y concurrencia;

c) La inclusión de cláusulas que estimularan al empresario a un correcto cumplimiento y sirvieran de salvaguarda al interés de la entidad en los casos de incumplimiento;

d) Cuando el volumen de la contratación lo justificara, los Consejos de Administración deberán aprobar instrucciones y pliegos generales para la contratación de obras y suministros.

13 Fernández Rodríguez, T.R. (1974), «¿Contratos administrativos entre personas privadas? Comentarios a la Sentencia del Tribunal Supremo de 16 de marzo de 1973", Revista Española de Derecho Administrativo, 1: 115 y ss; Garrigues Díaz-Cañavate. (1977), «Sobre la naturaleza jurídica de RENFE y su capacidad para celebrar contratos sometidos al Derecho mercantil», en el Libro Homenaje a Royo-Villanova, Madrid: Moneda y Crédito; Frank Maceda, B. (2001), «La sujeción a control contencioso-administrativo del fieri 42 de los contratos celebrados por ciertas sociedades mercantiles públicas: un remedio improcedente a una 
las personificaciones privadas y de los entes instrumentales sujetos al Derecho privado debía regirse precisamente por este sector del ordenamiento jurídico ${ }^{14}$.

En una fase posterior, el proceso de sujeción a normas públicas de la contratación de los entes instrumentales va poco a poco desapareciendo. La auténtica desbandada se produce mediante la reordenación del sector público a través de las Leyes de Presupuestos durante la década 1980-199015. Sin olvidar que este mismo planteamiento fue asumido por el legislador de las Comunidades Autónomas que comenzaron a crear empresas públicas para llevar a cabo actividades de interés general sin que su actividad contractual quedara sujeta a normas públicas. La huída del Derecho Administrativo alcanzó cotas tan alarmantes que el propio legislador aparentando tomar conciencia de ello intentó de forma «bastante discreta» poner ciertos límites a este fenómeno de privatización formal.

Y en 1995, bajo la presión de la necesidad de ajustar el ámbito de la contratación pública a los requisitos impuestos por el Derecho comunitario ${ }^{16}$, se aprobó la Ley 13/1995, de 18 de mayo, de Contratos de las Administraciones Públicas ${ }^{17}$ (LCAP), que

14 Esta posición partía de la tesis de que la existencia de un contrato administrativo requería la presencia de una Administración pública y, por tanto, los contratos de las personas jurídico-privadas, tenían exclusivamente naturaleza civil y debían regirse, consecuentemente por el Derecho privado. Los argumentos de esta postura doctrinal se hicieron patentes en los dictámenes que por aquélla época emitió el Consejo de Estado donde se muestra claramente la necesidad de la presencia de una Administración pública para aplicar el régimen contractual público, por lo que los contratos de los entes instrumentales en forma privada no podían aplicárseles esta normativa (Recopilación de Doctrina Legal del Consejo de Estado 1991, Dictámenes de 5 de septiembre y de 1 de octubre de 1991).

15 Hoy nos costaría creer el alcance de determinadas normas. Por ejemplo, el artículo 5.2 de la Ley 4/1980, de 10 de enero, establecía que Radiotelevisión Española estará sometida exclusivamente a su Estatuto (Ley 4/1980 y disposiciones complementarias), y en sus relaciones jurídicas externas, en las adquisiciones patrimoniales y en la contratación estará sujeta, sin excepción, al Derecho privado. El artículo 4.1 de La Ley 13/1994, de Autonomía del Banco de España, señalaba que no serán de aplicación al Banco de España las leyes que regulen el régimen presupuestario, patrimonial y de contratación de los entes del sector público estatal, salvo cuando se disponga expresamente lo contrario. En esta misma línea se situaba la Comisión Nacional del Mercado de Valores creada por Ley de 28 de julio de 1988, que en sus adquisiciones patrimoniales y contratación estaba sujeta, sin excepciones, al Derecho privado. No obstante, hoy desde otro contexto normativo la disposición adicional 12. ${ }^{\text {a }}$ de la LOFAGE también remite la regulación de la Corporación de Radio y Televisión Española, como sociedad anónima estatal dotada de especial autonomía respecto de la Administración General del Estado, a su Ley reguladora y a sus estatutos sociales; en segundo lugar, a la legislación sectorial y a las normas reguladoras de las sociedades mercantiles estatales $y$, en su defecto, al ordenamiento jurídico privado

16 Varias sentencias del TJCE condenaron a nuestro país por irregularidades en la adaptación normativa y en la práctica contractual en relación al marco contractual público europeo. La STJCE de 18 de marzo de 1992, Universidad Complutense, supuso el primer aviso sobre la incompatibilidad de nuestra contratación pública con el Derecho comunitario. Posteriormente, la Sentencia de 17 de noviembre de 1993, Asunto C-71/92, Comisión/España, volvió a cuestionar varios preceptos de la legislación española de contratos públicos. En el mismo sentido se pronunció la STJCE de 3 de mayo de 1994, Asunto C-328/92, que cuestionó la adjudicación directa de suministros farmacéuticos llevada a cabo por las Entidades Gestoras de la Seguridad Social, omitiendo la obligada publicación del anuncio en el DOCE.

17 El Consejo de Estado emitió un Dictamen sobre el anteproyecto de Ley de Contratos de las Administraciones Públicas donde reitera su vieja doctrina en relación a las sociedades mercantiles participadas mayoritariamente por la Administración, en las que la sujeción al Derecho privado es consecuencia 
vino a trazar un ámbito de aplicación subjetivo confuso y bastante complejo donde resultaba difícil encontrar un criterio delimitador ${ }^{18}$. Dejaba fuera de la aplicación de los procedimientos de licitación y adjudicación a los contratos celebrados por las sociedades mercantiles de capital íntegramente público, a los que sólo se les exigía el respeto a los principios de publicidad y concurrencia. La disposición adicional sexta, dedicada a los principios de contratación del sector público, estableció una cláusula general con un mínimo exigible, señalando que «las sociedades mercantiles en cuyo capital sea mayoritaria la participación directa o indirecta de las Administraciones públicas o de sus organismos autónomos, o entidades de derecho público, se ajustarán en su actividad contractual a los principios de publicidad y concurrencia, salvo que la naturaleza de la operación a realizar sea incompatible con estos principios». El contenido literal de esta disposición adicional de la LCAP pasó a formar parte íntegramente de la disposición adicional sexta del Texto Refundido de la Ley de Contratos de las Administraciones Públicas, aprobado por Real Decreto Legislativo 2/2000, de 16 de junio (TRLCAP). Desarrollado posteriormente por el Reglamento General de la Ley de Contratos de las Administraciones Públicas, Real Decreto 1098/2001, de 12 de octubre.

\subsection{Evolución normativa como consecuencia de la jurisprudencia comunitaria}

Es un hecho constatable que el ámbito subjetivo de aplicación de nuestra normativa contractual pública se ha ido modificando a golpe de sentencia del TJCE.

Dos han sido fundamentalmente las causas: $10^{\mathrm{a}}$ ) Cada vez con mayor frecuencia nuestro país ha confiado actividades de carácter público a entidades separadas de la organización administrativa clásica. 2.ª) De la compleja y confusa redacción del ámbito subjetivo de aplicación de nuestra normativa contractual pública, puede observarse la pretensión latente de la huída de sus propias previsiones ${ }^{19}$.

Frente a ello, la Comunidad Europea con el objetivo de orientar el buen funcionamiento del mercado ha considerado cuestión crucial del Derecho comunitario la de-

directa de su propia naturaleza. El dictamen no incorpora el concepto de empresa pública elaborado ya por el Derecho Comunitario (Dictamen número 1270 de diciembre de 1993).

18 El artículo 1 de la LCAP delimitó el ámbito de aplicación subjetivo estableciendo que los contratos que celebren las Administraciones públicas se ajustarán a las prescripciones de la presente Ley. Deberán asimismo ajustar su actividad contractual a la presente Ley, los organismos autónomos en todo caso y las restantes entidades de derecho público con personalidad jurídica propia, vinculadas o dependientes de cualquiera de las Administraciones públicas, siempre que en aquéllas se den los siguientes requisitos: a) que hayan sido creadas para satisfacer específicamente necesidades de interés general que no tengan carácter industrial o mercantil; b) que se trate de entidades cuya actividad esté mayoritariamente financiada por las Administraciones públicas u otras entidades de derecho público, o bien, cuya gestión se halle sometida a un control por parte de estas últimas, o cuyos órganos de administración, de dirección o de vigilancia están compuestos por miembros más de la mitad de los cuales sean nombrados por las Administraciones públicas y otras entidades de derecho público. Las entidades de derecho público que no cumplieran alguno de los mencionados requisitos, para determinados contratos especificados en el artículo 2 LCAP, quedaban sometidas a la normativa legal sobre la capacidad del

44 contratista, publicidad del contrato, procedimientos de licitación y formas de adjudicación. 
terminación de los sujetos contratantes ${ }^{20}$, por lo que reclama uniformidad del marco jurídico de la actividad de los agentes económicos que en él concurren ${ }^{21}$. Los objetivos pretendidos por la normativa comunitaria sobre contratación pública, se centran en la apertura de los mercados a las empresas nacionales de los distintos Estados miembros a través de la publicidad y de la concurrencia de las adjudicaciones y en el aumento de la competencia entre empresas oferentes ${ }^{22}$.

La interpretación jurisprudencial sobre el ámbito subjetivo de aplicación de las directivas comunitarias de contratación experimentó en 1998 un importante punto de inflexión, de manera que pueden distinguirse con claridad dos etapas diferenciadas en su evolución. Una primera, que va desde la creación de la Comunidad hasta 1998 , caracterizada por la escasez de pronunciamientos en esta materia ${ }^{23}$. Y una segunda que comienza en 1998 con importantes decisiones del Tribunal sobre el concepto funcional de poder adjudicador y la aplicación homogénea de los principios comunitarios a la contratación de los Estados miembros ${ }^{24}$.

20 La práctica, tan extendida en todos los países, de utilizar la contratación pública como un instrumento de política económica para poner en marcha medidas de lucha contra el desempleo, favorecer a determinadas regiones cuyo crecimiento convenía incentivar, y ayudar a las empresas nacionales, impedía la libre competencia de las empresas comunitarias y afectaba directamente a los derechos y libertades que el TCE pretendía garantizar.

21 Por la sencilla razón de que la desmembración formal de las Administraciones públicas no podía impedir la aplicación de la normativa comunitaria sobre contratación pública a las unidades desgajadas de la organización administrativa tradicional que ejerzan auténticas actividades públicas. Esta sujeción de los entes instrumentales a la normativa comunitaria sobre contratación pública ha sido uno de los objetivos perseguidos por la Comunidad en la última década.

22 El Libro Verde sobre contratación pública de 1996 pone de manifiesto la resistencia de los Estados miembros a abandonar la práctica de adjudicar los contratos públicos con criterios que poco tenían que ver con la calidad de las prestaciones y con el precio, así como la inadecuada transposición de las directivas comunitarias, el recurso excesivo al procedimiento negociado, la insuficiente publicidad, etc.

23 Los pronunciamientos jurisprudenciales sobre el concepto de poder o entidad adjudicadora eran muy escasos hasta ese momento y los pocos existentes se referían a esta materia de forma colateral. Vid. Montoya Marín, E. (2001), «La reciente jurisprudencia del Tribunal de Justicia de la Unión Europea acerca de poder adjudicador en las Directivas de contratación pública de servicios, suministros y obras», Revista Andaluza de Administración Pública, 41: 123; Aymerich Cano, C. (1999), «Entes instrumentales y Derecho comunitario de la contratación pública: el concepto de organismo de Derecho público», Cuadernos de Derecho Público, 6: 113-137; Fuertes López, M. (1999), «Personificaciones públicas y contratos administrativos. La última doctrina del Tribunal de Justicia de las Comunidades Europeas», Revista de Estudios de la Administración Local y Autonómica, 279: 25-34; Razquín Lizárraga, M. (2000), "La jurisprudencia del Tribunal de Justicia de las Comunidades Europeas sobre contratación pública», Justicia Administrativa, 6: 5-32; Moreno Molina, J.A. (2000), «La reciente jurisprudencia del Tribunal de Justicia de las Comunidades Europeas en materia de contratos públicos», Revista de Administración Pública, 151: 319-342; Trillo Torres, R. (2001), «El control judicial de la contratación administrativa», Justicia Administrativa, 10: 2-23.

24 Sin ánimo de exhaustividad cabe citar entre otras, las SSTJCE de 15 de enero de 1998, Asunto C-44/96, Mannesmann; de 10 de noviembre de 1998, Asunto 360/96, ARA; de 17 de diciembre de 1998, Asuntos Irish Forestry Board; de 27 de febrero de 2003, C-373/00, Adolf Truley; de 15 de mayo de 2003, Asunto 214/2000, Comisión/Reino de España; de 16 de octubre de 2003, Sociedad Estatal de Infraestructuras y Equipamientos Penitenciarios (SIEPSA); de 13 de enero de 2005, C-84/2003, Comisión/Reino de España; de 2 de junio de 2005, Koppensteiner GMBH; y de 13 de diciembre de 2007, Bayerischer. 
Las primeras directivas comunitarias sobre contratación pública del año 1971 consideraron poderes adjudicadores al Estado, a las colectividades territoriales, y a las personas jurídicas de Derecho público enumeradas en sus anexos. La interpretación del concepto de «persona jurídica de derecho público» no estuvo exenta de cierta confusión, pues, se podía interpretar como referida exclusivamente a las personificaciones públicas sometidas al Derecho público, o también a las personificaciones públicas sometidas al Derecho privado y, por supuesto, excluía a las personas jurídicas de Derecho privado a pesar de que desarrollaran actividades de carácter público. Estas dudas quedaron zanjadas en la STJCE de 20 de septiembre de 1988, Beentjes/ Países Bajos"25, al considerar el Tribunal que «cuando un organismo, cuyos miembros son designados por autoridades del Estado o de una colectividad territorial, está encargado de una actividad comprendida en las competencias normales de estos y dotado para ello de los medios que le permiten cumplirla, se le calificará como poder adjudicador ${ }^{26}$.

Este pronunciamiento jurisprudencial fue determinante para modificar el ámbito de aplicación de las directivas comunitarias sobre contratación pública de los años setenta ${ }^{27}$. La Directiva 89/440/CEE, de 18 de julio de 1989, recogiendo la doctrina del TJCE, dota de un nuevo alcance al ámbito subjetivo de aplicación, entendiendo por poderes adjudicadores además del Estado y de las entidades territoriales, a los «organismos de derecho público» que hayan sido creados para satisfacer específicamente necesidades de interés general que no tengan carácter mercantil o industrial, dotados de personalidad jurídica y cuya actividad esté mayoritariamente financiada, organizada, o controlada por el Estado, los entes territoriales u otros organismos de derecho público. Este nuevo concepto de «organismo de derecho público», se detalla minuciosamente por la Directiva 89/440/CEE para evitar escapes injustificados.

Esta definición comunitaria de «organismo de derecho público» sólo permitía excluir a las empresas públicas con forma societaria que realicen exclusivamente una actividad mercantil en el sentido de dación y transformación de bienes al mercado ${ }^{28}$. Este amplio ámbito subjetivo de aplicación lo incorporaron posteriormente de forma literal las Directivas comunitarias sobre contratación pública de 1992-1993 (servicios,

25 Se enjuiciaba la contratación realizada por una Comisión local belga sin personalidad jurídica propia que no podía considerarse Estado, ni colectividad territorial ni tampoco persona jurídica de Derecho público.

26 En las conclusiones el abogado general especificaba claramente que el fenómeno de la desmembración de las Administraciones públicas no debe impedir la extensión de la normativa comunitaria de contratos públicos a aquellas unidades desmembradas de la organización administrativa tradicional que sigan ejerciendo auténticas actividades públicas. Este carácter funcional de poder público permite extender la aplicación de las primeras directivas a entes instrumentales en forma privada cuando ejerzan actividades administrativas y públicas.

27 Directiva 71/305/CEE, sobre contratos públicos de obras y Directiva 77/62/CEE sobre contratos públicos de suministro.

28 Del Saz Cordero, S. (1993), «Los contratos de la Administración y el Derecho comunitario», op., 46 cit., p. 226. 
obras y suministros) $)^{29}$, que adoptan una definición funcional de poder adjudicador. Como vemos desde 1989 el ámbito de aplicación de la normativa comunitaria incluye a los entes públicos, sociedades públicas y fundaciones de interés público que satisfagan específicamente necesidades de interés general, y cuya actividad esté mayoritariamente financiada, organizada o controlada por el Estado, los entes territoriales u otros organismos de derecho público.

A pesar de ello, algunos Estados miembros seguían utilizando el recurso de constituir personificaciones privadas para realizar actividades de interés general con la clara intención de evadir la normativa contractual comunitaria. Un ejemplo lo encontramos en el ámbito subjetivo de aplicación de la LCAP de 1995 que no recoge fielmente la noción de "organismo de derecho público», a pesar de que las Directivas comunitarias sobre contratación pública llevaban varios años en vigor.

Ante esta sistemática y reiterada inaplicación de la normativa contractual comunitaria irrumpe el TJCE precisando y concretando el concepto de poder adjudicador para evitar escapes injustificados. La STJCE de 15 de enero de $1998^{30}$ es buen ejemplo de ello: «cuando las funciones o actividades atribuidas a los organismos de derecho público sean de interés general, aunque sólo constituyan una parte irrelevante de las actividades emprendidas por los mismos, el dato de su personificación privada, no excluirá la aplicación de las normas comunitarias de contratación pública» ${ }^{31}$. Sin embargo, cuando la finalidad que motiva su creación sea exclusivamente la realización de actividades industriales o comerciales, los contratos que celebren en el ejercicio de dicha actividad, estarán sometidos a los principios comunitarios del sector público: igualdad, no discriminación, publicidad y concurrencia.

29 Directivas 93/37/CEE y 93/36/CEE, de 14 de junio, sobre coordinación de los procedimientos de adjudicación de los contratos de obras públicas y suministros, respectivamente, y Directiva 92/50/CEE, sobre coordinación de los procedimientos de adjudicación de los contratos de servicios. Únicamente existía una pequeña variación nominal en la Directiva de servicios (92/50/CEE) que utilizaba el concepto de «entidad adjudicadora» en lugar de poder adjudicador, debido a que el tipo de actividad a la que iba dirigida se prestaba más en régimen de gestión empresarial que como ejercicio de autoridad, es decir, como poder público.

30 Asunto C-44/96, Mannesmann Anlagenbau Austria AG y otros, contra Strohal Rotationsdruch GesmbH, Rec. 1998-I, pp. 73-122. En especial las conclusiones del abogado general Sr. Philippe LEGER. Un detallado estudio de la sentencia puede verse en mi trabajo las sociedades mercantiles en manos de las Administraciones públicas: principios de publicidad y concurrencia. Fundamentos de su publificación, Tirant lo Blanch, Valencia, 2003, pp. 69 a 82.

31 La Sentencia resuelve una cuestión prejudicial planteada por un tribunal de justicia austriaco como consecuencia de un recurso contra la resolución de la Comisión Federal de Control de las Licitaciones, que consideró que la licitación de un proyecto relativo a las instalaciones técnicas de la imprenta nacional austriaca no debía ajustarse a la licitación pública, a pesar de tratarse de un organismo de naturaleza pública. La imprenta nacional del Estado austriaco estaba constituida como una entidad económica autónoma con la condición de comerciante en el sentido del Código mercantil y sus actividades fundamentales, como la producción de impresos y documentos, la edición y distribución de libros y periódicos, estaban sometidas a las normas mercantiles. Sólo una pequeña parte de las mismas, la impresión de pasaportes, permisos de conducir, documentos de identidad y el Diario Oficial Federal podían ser calificadas de interés general. 
Le mueve al Tribunal a tener en cuenta, al margen de la personalidad jurídica, la misión específica de interés general que motiva la creación de estos «organismos de derecho público», a pesar de que puedan realizar en mayor medida otras actividades de carácter industrial o mercantil ${ }^{32}$. La finalidad específica de su creación es determinante para poder considerar a un organismo de derecho público como poder o entidad adjudicadora a los efectos de la normativa comunitaria sobre contratación pública33.

Con esta doctrina jurisprudencial tan clara y precisa acerca de los sujetos contratantes sometidos a la normativa comunitaria, el legislador español seguía sin incorporar fielmente el concepto de organismo de derecho público a nuestra normativa contractual pública34, a pesar de las reformas llevadas a cabo en 1999 y 2000. Por ello, la STJCE de 15 de mayo de 2003, Asunto C-214/2000 (Comisión/España), condena a nuestro país por inaplicación y falta de transposición de las directivas comunitarias, en concreto, de la Directiva denominada de recursos $89 / 665^{35}$, y por la exclusión del ámbito de aplicación del TRLCAP de las sociedades mercantiles públicas que realizan actividades de interés general ${ }^{36}$. En el mismo sentido se pronuncia la STJCE de 16 de octubre de 2003, que condena de nuevo a nuestro país por inaplicación del Derecho comunitario de contratación pública ${ }^{37}$. Estas condenas obligaron al legislador español

32 La actividad de carácter público tiene una vis atractiva hacia el Derecho público respecto de cualquier otra actividad que desarrolle el organismo por muy mercantil o industrial que sea, debiendo entenderse sometido a las reglas de la contratación pública. Véase la STJCE de 10 de noviembre de 1998, asunto C-360/96, Rec. I-1998, 11, BFI Holding, donde el Tribunal distingue entre necesidades de interés general que tienen carácter industrial o mercantil y necesidades de interés general que no tienen ese carácter. Afirmando que no es óbice que empresas privadas que actúan en régimen de mercado puedan realizar actividades de interés general, es decir, la competencia en el mercado por sí sola no supone descalificación de la actividad desarrollada como de interés general.

33 En la STJCE de 1 de febrero de 2001, Asunto C-237/1999, el Tribunal no tiene en cuenta la forma y régimen jurídico de una sociedad anónima de viviendas de alquiler moderado francesa, sino la concurrencia de los requisitos acumulativos que sobre el concepto de «organismo de derecho público» exigen las Directivas comunitarias.

34 Recordemos que la LCAP de 1995 fue modificada en 1999 y 2000. El Texto Refundido de la Ley de Contratos de las Administraciones Públicas, aprobado por Real Decreto Legislativo 2/2000, de 16 de junio, vuelve a reproducir literalmente el ámbito subjetivo de aplicación de su antecesora, sin que el legislador español se hiciera eco de las modificaciones normativas comunitarias ni de los pronunciamientos jurisprudenciales sobre esta materia. Véase Villalba Pérez, F. (2003), La contratación de las sociedades mercantiles en manos de las Administraciones públicas: principios de publicidad y concurrencia. Fundamentos de su publificación, Valencia: Tirant lo Blanch.

35 Modificada por la Directiva 2007/66/CE, de 11 de diciembre, que pretende reforzar las garantías de cumplimiento de las normas europeas de contratación pública.

36 La Sentencia señala que no cabe interpretar por parte de los Estados miembros que del concepto de organismo de derecho público incluido en las directivas comunitarias sobre contratación pública, ni de los principios elaborados por la jurisprudencia de este tribunal, puedan excluirse como entidades adjudicatarias a las sociedades mercantiles públicas que realizan actividades de interés general, ni mucho menos dejarlas fuera del ámbito de aplicación de las directivas comunitarias sobre contratación pública.

37 Enjuicia el TJCE si la Sociedad Estatal de Infraestructuras y Equipamientos Penitenciarios (SEIEPSA) de capital $100 \%$ público, creada por el Ministerio de Justicia con la finalidad de canalizar la construcción y gestión de las cárceles y demás infraestructuras penitenciarias, puede ser considerada como organismo de derecho público y, por tanto, poder adjudicador a efectos de la Directiva 93/37 sobre el contrato de obra pública. Para el TJCE el concepto de organismo de derecho público no se identifica con el concepto nacional de Administración pública ni de entidad de derecho público, sino que es mucho más amplio. 
a modificar rápidamente el ámbito subjetivo de aplicación de nuestra normativa contractual pública para adaptarlo a la normativa comunitaria. Reforma que se llevó a cabo mediante la Ley 62/2003, de 30 de diciembre, de medidas fiscales, administrativas y del orden social, que incluyó en el artículo 2.1del TRLCAP ${ }^{38}$ a las sociedades mercantiles públicas, y añade un nuevo artículo 60 bis sobre garantías para recurrir39.

Posteriormente, la STJCE el 13 de enero de 2005, vuelve a condenar a España por incumplimiento del ámbito subjetivo y por la inadecuada utilización de la técnica del convenio interadministrativo y del procedimiento negociado. Esta nueva condena obliga de nuevo al legislador a modificar el ámbito subjetivo de aplicación de nuestra normativa contractual e incluir, en este caso, a las fundaciones de iniciativa pública. Modificación llevada a cabo por el Real Decreto Ley 5/2005, de 11 de marzo ${ }^{40}$. Por último, como tampoco cumplió nuestro país el plazo otorgado por la Directiva 2004/18/CE ${ }^{41}$ para su incorporación a nuestro ordenamiento interno ${ }^{42}$, la Ley 42/2006, de 28 de diciembre, de Presupuestos para el año 2007, vuelve a modificar el ámbito subjetivo de aplicación para dejar de lado la manera tradicional de identificar a las entidades de derecho privado, fijando una definición acorde con los criterios de la Directiva comunitaria43.

38 El artículo modificado sujeta a la normativa del TRLCAP la capacidad del contratista, la publicidad del contrato, los procedimientos de licitación y las formas de adjudicación de los contratos celebrados por las entidades de derecho público que no cumplan los requisitos establecidos en el artículo 1.3 del TRLCAP, así como los contratos celebrados por sociedades mercantiles de capital mayoritario o exclusivamente público siempre que hubiesen sido creadas específicamente para satisfacer necesidades de interés general, su presupuesto supere una determinada cuantía y concurra en ellas alguno de los requisitos de dependencia que especifica el apartado b) del artículo 1.3 del TRLCAP.

39 Véase García de Enterría, E. (2003), «El Tribunal de Justicia de las Comunidades Europeas constata y censura dos graves quiebras de nuestro Derecho administrativo en materia de entes sujetos al Derecho público y de medidas cautelares contencioso-administrativas", Revista Española de Derecho Administrativo, 119. Del mismo autor (2003), «Una nueva sentencia del Tribunal de Justicia de las Comunidades Europeas sobre la sumisión a las normas comunitarias de contratación pública de las sociedades mercantiles de titularidad de las Administraciones públicas (Sentencia Comisión contra España de 16 de octubre de 2003, (-283/2000)", Revista Española de Derecho Administrativo, 120: 667-677.

40 De medidas urgentes para el impulso de la productividad y para la mejora de la contratación pública. Este Real Decreto-Ley incorpora al ámbito subjetivo del TRLCAP a las fundaciones del sector público para solucionar los problemas derivados de la ausencia de aplicación de las normas comunitarias sobre procedimientos de adjudicación cuando gestionan proyectos financiados con fondos europeos.

41 La Comisión Europea interpuso el 30 de mayo de 2007 un recurso contra España (asunto C-255/2007) para que el Tribunal declare que ha incumplido las obligaciones que le incumben al no haber adoptado las disposiciones legales, reglamentarias y administrativas necesarias para ajustarse a la Directiva 2004/18/CE, sobre coordinación de los procedimientos de adjudicación de los contratos públicos de obras, suministro y servicios.

42 Vid. Jiménez Blanco, A. (2002), «De nuevo sobre el efecto directo de las Directivas», Noticias de la Unión Europea, 205: 115-120. El autor señala que el incumplimiento del plazo de transposición -habitual en esta materia- se debe a varias causas. Una, sin duda de relevancia, es la mecánica con la que en España se realiza la transposición del Derecho Comunitario, siguiendo los trámites ordinarios de todo procedimiento para elaborar una ley. Práctica que en muchos casos ya resulta de por sí incompatible con los plazos de transposición.

43 Véase la Resolución de la Junta Consultiva de la Contratación Administrativa de 2 de abril de 2007, que hace público el Acuerdo de 30 de marzo de 2007, por el que se adoptan criterios interpretativos para la aplicación del artículo 2.1 del TRLCAP tras la reforma operada por la disposición final $4 .^{\text {a }}$ de la Ley 42/2006, de 28 de diciembre. 
Ante esta resistencia a cumplir el contenido de las directivas comunitarias sobre contratación pública, justificada, en muchos casos, en la rigidez de sus procedimientos y en sus excesivas exigencias, la Unión Europea impulsó una actualización y agilización de los procedimientos contractuales mediante la aprobación de la Directiva 2004/18/CE, de 31 de marzo ${ }^{44}$, con la firme convicción de erradicar las excusas que alegaban los Estados miembros para justificar su persistente inaplicación de la normativa comunitaria.

\section{CONTRATACIÓN DE LOS ENTES DEL SECTOR PÚBLICO NO CONSIDERADOS ADMINISTRACIÓN PÚBLICA EN LA LEY DE CONTRATOS DEL SECTOR PÚBLICO}

\section{1. Ámbito subjetivo y niveles de aplicación de la LCSP}

La Ley 30/2007, de 30 de octubre, de Contratos del Sector Público (en adelante LCSP), tiene como objetivo prioritario incorporar el contenido de la Directiva 2004/18/ CE a nuestro ordenamiento interno. Pero a la vez el legislador ha aprovechado la ocasión para introducir algunas modificaciones en la regulación contractual pública. Así lo señala la exposición de motivos al afirmar que la delimitación de los entes sujetos a la Ley se realiza en términos muy amplios a fin de ajustar su ámbito de aplicación al de las directivas comunitarias, no dejando entidades del sector público exentas de regulación. Veamos si las buenas intenciones del legislador son plasmadas posteriormente en la redacción de su articulado.

La Ley tiene por objeto garantizar que la contratación del sector público se ajusta a los principios de concurrencia, publicidad y transparencia, no discriminación e igualdad de trato entre candidatos, así como velar por una eficiente utilización de los fondos públicos mediante la exigencia de la definición previa de las necesidades a satisfacer, y de asegurar la selección de la oferta económicamente más ventajosa (artículo 1 LCSP). Añadiendo el artículo 2 que quedan sujetos a su ámbito de aplicación en la forma y en los términos previstos en la misma, los contratos que celebren los entes, organismos y entidades del sector público, cualquiera que sea su naturaleza jurídica. También los contratos subvencionados por el sector público que celebren otras personas físicas y jurídicas en los supuestos previstos en el artículo 17, así como los contratos de obras que celebren los concesionarios de obras públicas según lo establecido en el artículo 250.

44 Sobre coordinación de los procedimientos de adjudicación de los contratos públicos de obras, suministro y servicios. Toda la regulación de la contratación pública, excepto la relativa a los servicios especiales, ha sido unificada por la Directiva 2004/18/CE que sustituye a las directivas clásicas que regulaban cada uno de los contratos: Directiva 92/50/CEE, sobre contratos públicos de servicios; Directiva 93/36/CEE, sobre suministros; y Directiva 93/37/CEE, relativa a los contratos públicos de obras. 
Por su parte El artículo 3 LCSP dedicado a regular el ámbito de aplicación subjetivo enumera los entes, organismos y entidades que forman parte del sector público incluyendo tres tipos de sujetos contratantes ${ }^{45}$ :

a) Administraciones públicas (artículo 3.2), describiendo las entidades que tienen esta consideración ${ }^{46}$;

b) Poderes adjudicadores (artículo 3.3), en cuya categoría se incluyen no sólo las Administraciones públicas, sino también a todos aquellos entes, organismos o entidades con personalidad jurídica propia distintos de las Administraciones públicas que hayan sido creados específicamente para satisfacer necesidades de interés general que no tengan carácter industrial o mercantil, siempre que uno o varios sujetos considerados poderes adjudicadores financien mayoritariamente su actividad, controlen su gestión o nombren a más de la mitad de los miembros de su órgano de administración, dirección o vigilancia. Se consideran también poderes adjudicadores las asociaciones constituidas por los entes, organismos o entidades que tienen este carácter ${ }^{47}$.

45 Gimeno Feliu señala que una interpretación literal de los artículos 2 y 3 LCSP podrían llevar a la conclusión de dejar fuera del alcance de la Ley a determinados contratos del sector público, lo que obliga a reinterpretaciones conformes al Derecho Comunitario. Considera que hubiera sido más lógico definir previamente el concepto de poder adjudicador y su interpretación conforme a la jurisprudencia comunitaria, antes que los distintos sujetos contratantes sometidos a la Ley, como acertadamente hace la Ley Foral Navarra de Contratos Públicos de 2006. Gimeno Feliu, J.M. (2008), «Nuevo ámbito subjetivo de aplicación de la Ley de Contratos del Sector Público", Revista de Administración Pública, 176: 40.

46 Tendrán la consideración de «Administraciones Públicas» los entes territoriales, las entidades gestoras de la Seguridad Social, los organismos autónomos, las universidades públicas, los organismos reguladores y las entidades de derecho público dependientes de una Administración cuya actividad principal no sea mercantil ni sus recursos procedan del mercado. En esta última descripción quedarían comprendidos, a nuestro juicio, los contratos de los consorcios y de las agencias públicas que cumplan alguno de los dos requisitos señalados en la letra e) del artículo 3.2 LCSP, por lo que las fases de preparación, adjudicación, ejecución y extinción quedarían sometidas a las prescripciones de la LCSP, al margen del importe del contrato. Sin embargo, no tendrán la consideración de Administraciones públicas las entidades públicas empresariales estatales y los organismos asimilados dependientes de las Comunidades Autónomas y de las Entidades Locales. Tampoco los entes incluidos en la disposición adicional 25. ${ }^{\text {a: }}$ Museo del Prado, Instituto Español de Comercio Exterior, Sociedad Estatal de Participaciones Industriales, Ente Público Puertos del Estado y Autoridades Portuarias, a pesar de que son entes públicos cuya actividad principal es de interés general, y no se financian a través de contraprestaciones del mercado. Sí se equiparan a las Administraciones públicas las Diputaciones Forales y las Juntas Generales, los órganos constitucionales del Estado y los órganos legislativos y de control de las Comunidades Autónomas, que tendrán por expreso deseo del legislador el mismo tratamiento en lo que respecta a su actividad contractual (disposición adicional $3 .{ }^{\text {a }}$ LCSP). Véase Sosa Wagner, F. (2008), «La Ley de Contratos del Sector Público y el murciélago», Actualidad jurídica Aranzadi, 743, de 17 de enero de 2008; Gimeno Feliu, J.M. (2008), «El nuevo ámbito de aplicación de la Ley de Contratos del Sector Público», op., cit., p. 45. Blanquer, D. (2007), La nueva Ley de Contratos del Sector Público, Valencia: Tiran lo Blanch, pp. 35-36.

47 Según el artículo 3.3 LCSP son «poderes adjudicadores» además de las Administraciones públicas, los organismos de derecho público destinatarios de la Directiva 2004/18/CE, y las asociaciones constituidas por los entes, organismos y entidades que a su vez sean considerados poderes adjudicadores. Así junto a las Administraciones públicas, se consideran poderes adjudicadores a las entidades públicas empresariales, las fundaciones públicas, las sociedades públicas, los consorcios integrados por personificaciones 


\section{c) Demás entes del sector público (artículo 3.1) ${ }^{48}$. En este apartado la LCSP inclu- ye a los demás sujetos que forman parte del sector público.}

La intensidad de aplicación de la LCSP depende justamente de esta división: aplicación máxima para las Administraciones públicas ${ }^{49}$; aplicación media, para los poderes adjudicadores ${ }^{50}$, y aplicación mínima, para los demás sujetos del sector público ${ }^{51}$. Pero a la vez, para determinar correctamente el régimen jurídico del contrato, hay

privadas, las mancomunidades que no cumplan alguno de los requisitos establecidos en el artículo 3.2 apartado e), etc. Se trata de entidades de Derecho público y entidades de Derecho privado no consideradas Administración pública pero pertenecientes al sector público, siempre que cumplan con los requisitos del artículo 1.9 de la citada Directiva para ser considerados poderes adjudicadores.

48 Con la denominación de «demás entes del sector público», la LCSP intenta sujetar de forma muy flexible la contratación de las entidades y organismos del sector público que no son poderes adjudicadores por no estar sometidos a la normativa comunitaria. Teniendo en cuenta que los requisitos exigidos por el artículo 3.3 LCSP para ser considerado poder adjudicador son acumulativos, la falta de cualquiera de ellos implicará la inaplicación de las Directivas y, en consecuencia, sus contratos nunca serán contratos sometidos a regulación armonizada. Es el caso de aquellas entidades y organismos creados para satisfacer actividades de carácter industrial o mercantil, o que no estén controlados o financiados por los poderes públicos. Todos los señalados en el artículo 3.1 LCSP que no tengan el carácter de Administraciones públicas ni de poderes adjudicadores.

49 A los contratos celebrados por las Administraciones públicas, sobre todo, si se trata de contratos administrativos, se les aplicará con mayor intensidad el contenido de la LCSP. Así lo señala el artículo 19.2 LCSP al determinar que los contratos administrativos se regirán, en cuanto a su preparación, adjudicación, efectos y extinción, por esta Ley y sus disposiciones de desarrollo, supletoriamente se aplicarán las restantes normas de derecho administrativo y, en su defecto, las normas de derecho privado. A los contratos administrativos especiales les será de aplicación, en primer término, sus normas específicas. Como vemos, las exigencias de la LCSP para los contratos celebrados por las Administraciones públicas, con independencia de que estén o no afectados por la normativa comunitaria, van más allá de lo establecido en el Derecho comunitario. Si se trata de contratos privados celebrados por las Administraciones Públicas, el artículo 21 LCSP sujeta a sus previsiones los actos preparatorios y la adjudicación, en defecto de normas específicas, remitiendo a las normas de Derecho privado los efectos y extinción del contrato.

50 La aplicación de la LCSP a la actividad contractual de los poderes adjudicadores es mucho menos intensa que para las Administraciones públicas, la Ley se limita a transponer las prescripciones que en relación a la publicidad, licitación y adjudicación de los contratos públicos impone la Directiva 2004/18/CE. En los contratos celebrados por los poderes adjudicadores hay que diferenciar los sujetos a regulación armonizada de los que no lo están. Para los primeros, los sometidos a regulación armonizada, serán de aplicación muchas de las normas previstas para las Administraciones públicas sobre la preparación del contrato, y en cuanto a la adjudicación, las normas aplicables son las mismas que para la Administración, aunque las exigencias de publicidad quedan un poco rebajadas pues se les exime de la publicidad en los diarios oficiales internos, la cual se sustituye por la inserción de la convocatoria en la denominada Plataforma de Contratación del Estado, manteniéndose la exigencia de publicidad en el DOUE. En cuanto al resto de contratos de los poderes adjudicadores, los no sometidos a regulación armonizada, las exigencias de la LCSP son infinitamente menores, ya que no se aplican procedimientos reglados de licitación, los cuales se sustituyen por la aplicación de los principios de publicidad, concurrencia, transparencia, confidencialidad, igualdad y no discriminación. Los procedimientos reglados de adjudicación son sustituidos por instrucciones internas de obligado cumplimiento.

51 La actividad contractual de las entidades y organismos del sector público que no son Administración pública ni poderes adjudicadores, sólo está sometida a las reglas generales establecidas para todos los contratos del sector público, en concreto las relativas a la idoneidad del contrato; los criterios generales para determinar su duración; las reglas sobre el contenido mínimo; información al Tribunal de Cuentas; el perfil del contratante; las relativas a la capacidad y a algunas prohibiciones de contratar (artículo 49.1 LCSP). En cuanto a la adjudicación del contrato, la LCSP exige la aplicación de los principios generales y recuerda la necesidad de que el contrato sea adjudicado a la oferta económica más ventajosa. Ambas obligaciones deberán concretarse en sus normas internas publicadas en el perfil del contratante. 
que tener en cuenta su tipología, objeto y la cuantía de su presupuesto, para someterlo o no a regulación armonizada. Cuestiones que pasamos a estudiar.

\subsection{Tipología contractual de la LCSP}

Desde el punto de vista del sujeto contratante, la LCSP clasifica los contratos del sector público en contratos administrativos o contratos privados. Tienen carácter administrativo los contratos celebrados por las Administraciones públicas que se regirán en cuanto a su preparación, adjudicación, efectos y extinción, por las previsiones de la LCSP y su desarrollo reglamentario (artículo 19 LCSP). Tienen carácter privado, además de los contratos celebrados por la Administración pública con tal carácter, los celebrados por los entes, organismos y entidades del sector público que no reúnan la condición de Administración pública (artículo 21.1). A los contratos privados del sector público les será de aplicación los preceptos de la LCSP en cuanto a su preparación y adjudicación, quedando fuera de su ámbito de regulación los efectos y extinción del contrato, que se sujetarán al Derecho privado. Por tanto, los contratos celebrados por los entes, organismos y entidades que no son Administración pública, tienen a todos los efectos la consideración legal de contratos privados. No obstante, los contratos privados a su vez pueden estar sujetos a regulación armonizada o no estarlo, distinción, con importantes consecuencias en el régimen jurídico de sus actos de preparación y adjudicación del contrato, así como en su posible impugnación.

Según el objeto y contenido del contrato, la LCSP califica los contratos del sector público en contratos de obras; contratos de concesión de obras públicas; contratos de gestión de servicios públicos; contratos de suministro; contratos de servicios; y contrato de colaboración entre el sector público y el sector privado ${ }^{52}$. De estas seis categorías, los entes, organismos y entidades que no tienen carácter de Administraciones públicas, solo podrán celebrar tres de ellas: contrato de obras, contrato de suministro y contrato de servicios, ya que las restantes modalidades quedan excluidas de su ámbito de actuación de forma expresa o implícitamente. El contrato de colaboración entre el sector público y el sector privado (artículo 11), y el contrato de gestión de servicio público (artículo 8), quedan reservados de forma expresa a las Administraciones públicas y, por tanto, excluidos a otros entes del sector público. El contrato de concesión de obra pública, aunque de forma expresa no queda reservado a la Administración pública por el artículo 7 LCSP, puede deducirse por las constantes remisiones que su regulación hace a favor de «la Administración concedente» que el legislador ha querido realizar una reserva implícita53.

52 Con la LCSP desaparece el contrato de consultoría y asistencia que queda incluido o encuadrado en el contrato de servicios, y aparece una nueva categoría, el contrato de colaboración entre el sector público y el sector privado.

53 Véanse los artículos 112, 113 y 114 de la LCSP, relativos a los actos preparatorios del contrato de concesión de obra pública, que contienen la expresión «Administración concedente». Y esta fase contractual es la determinante al tratarse de contratos privados. Ya que los artículos 223 a 250 LCSP que regulan la ejecución del contrato administrativo de concesión de obra pública, hacen referencia expresa a la «Administración concedente». 
También hay que tener en cuenta las posibles combinaciones de prestaciones correspondientes a varios tipos contractuales que puedan incluir los entes del sector público en sus contratos, se trata de los denominados contratos mixtos, a los que el artículo 12 LCSP sujeta para la determinación de las normas que deban observarse en su adjudicación, a las del tipo contractual que tenga más importancia desde el punto de vista económico ${ }^{54}$.

Por la cuantía económica del contrato, la LCSP distingue entre contratos sujetos a regulación armonizada y los no sujetos a esta regulación. Los contratos sujetos a regulación armonizada son aquellos que por razón de la entidad contratante (poder adjudicador), tipo contractual 55 y la cuantía de su presupuesto, quedan sometidos a las directrices comunitarias, en concreto a las previsiones de la Directiva 2004/18/CE que la LCSP incorpora ${ }^{56}$. En los no sujetos a regulación armonizada el legislador nacional tiene mayor libertad en la configuración de su régimen jurídico. Los artículos 13 a 17 LCSP determinan, según el objeto contractual, los contratos que se encuentran sometidos a regulación armonizada para lo que exige que el sujeto contratante sea considerado poder adjudicador.

En el caso que nos ocupa, de acuerdo con la tipología contractual diseñada por la LCSP para los entes públicos no considerados Administración pública, estarán sujetos a regulación armonizada los contratos de obras cuyo presupuesto ascienda a 5.150.000 euros, y los contratos de suministro y de servicios por importe superior a 133.000 ó 206.000 euros $^{57}$. También quedarán sujetos a regulación armonizada los contratos que cumpliendo los requisitos establecidos en el artículo 17 LCSP celebren los particulares o las entidades del sector público que no tengan la consideración de poderes adjudicadores cuando hayan sido subvencionados en más de un 50\% de su importe por entidades consideradas poderes adjudicadores. Por último, cuando el importe del contrato sea inferior a 50.000 euros si se trata de contratos de obras, 018.000 euros si se trata de otros contratos, la LCSP los califica como contratos menores ${ }^{58}$.

54 Nada dice el precepto acerca de los actos de preparación del contrato, por lo que deberemos entender que la normativa a aplicar en esta fase contractual seguirá los criterios generales de la Ley en cuanto al sujeto contratante y a la cuantía del contrato.

55 Concreta el artículo 13 LCSP que quedarán sujetos a regulación armonizada los contratos de colaboración entre el sector público y el sector privado, en todo caso, y los contratos de obras, los de concesión de obras públicas, los de suministro, y los de servicios comprendidos en las categorías 1 a 16 del Anexo II, cuyo valor estimado supere los umbrales comunitarios.

56 El artículo 13 LCSP considera que un contrato quedará sometido a regulación armonizada cuando concurran las siguientes condiciones: a) que la entidad contratante tenga el carácter de poder adjudicador; b) que su valor estimado conforme a las reglas que establece el artículo 76 sea igual o superior a las cuantías que para cada uno de los indicados tipos establecen los artículos 14 (contrato de obras), 15 (contrato de suministro) y 16 (contratos de servicios comprendidos en las categorías 1 a 16 del Anexo II) de la LCSP. En consecuencia, faltando alguno de los dos requisitos, el contrato no tendrá la consideración de contrato sujeto a regulación armonizada.

57 Véanse los apartados a) y b) de los artículos 15 y 16 LCSP.

58 Establece el artículo 122.3 LCSP que se consideran contratos menores los de importe inferior a 50.000 euros, si se trata de contratos de obras, o a 18.000 euros, cuando se trate de otros contratos. Los contratos menores podrán adjudicarse directamente a cualquier empresario con capacidad de obrar y que 
Alos contratos celebrados por entidades distintas a las Administraciones públicas, la LCSP los considera contratos privados, aunque puedan estar sometidos a regulación armonizada, quedémonos con este dato.

\subsection{Jurisdicción competente para conocer las cuestiones suscitadas en los contratos de los entes del sector público.}

Especifica el artículo 21 LCSP que corresponderá al orden jurisdiccional contencioso-administrativo resolver las cuestiones litigiosas relativas a la preparación, adjudicación, efectos, cumplimiento y extinción de los contratos administrativos. Igualmente, este orden jurisdiccional conocerá de las cuestiones que se susciten en relación a la preparación y adjudicación de los contratos privados de las Administraciones públicas y de los contratos sujetos a regulación armonizada celebrados por poderes adjudicadores, incluidos los contratos subvencionados.

El orden jurisdiccional civil será el competente para resolver las controversias que surjan entre las partes en relación con los efectos, cumplimiento y extinción de los contratos privados. También conocerán los tribunales civiles de cuantas cuestiones litigiosas afecten a la preparación y adjudicación de los contratos privados celebrados por entes que no tengan la consideración de Administración pública, siempre que no sean contratos sujetos a regulación armonizada.

El control por la jurisdicción contencioso administrativa de las cuestiones relativas a la preparación y adjudicación de los contratos privados se extiende por imperativo del artículo 21 de la LCSP no sólo a los contratos que celebren las Administraciones públicas, sino también a los contratos sujetos a regulación armonizada celebrados por las demás entidades del sector público (entidades públicas empresariales, sociedades mercantiles públicas, fundaciones), así como a los contratos celebrados por particulares cuando estén subvencionados. Esta solución ha sido acogida de forma favorable por la mayoría de la doctrina debido al carácter administrativo de la normativa contractual pública y a la demostrada experiencia jurídico-pública de la jurisdicción contencioso administrativa.

Sin embargo, el artículo 21.2 LCSP atribuye a los Tribunales ordinarios el control de todas las fases contractuales: preparación, adjudicación, efectos y extinción, de los contratos privados no sujetos a regulación armonizada, celebrados por entes no considerados Administración pública (poderes adjudicadores y demás entes del sector público). Resulta paradójico que los Tribunales civiles sean los llamados a conocer

cuente con la habilitación profesional necesaria para realizar la prestación. La tramitación del expediente sólo exigirá la aprobación del gasto y la incorporación al mismo de la factura correspondiente, que deberá reunir los requisitos normativos exigidos. En el contrato menor de obras, deberá añadirse, además, el presupuesto de las obras, sin perjuicio del correspondiente proyecto cuando normas específicas así lo requieran. Deberá igualmente solicitarse el informe de supervisión a que se refiere el artículo 109 LCSP cuando el trabajo afecte a la estabilidad, seguridad o estanqueidad de la obra (artículo 95 LCSP). 
de las controversias surgidas en la aplicación de normas jurídico-administrativas, como las disposiciones generales de la LCSP para todos los contratos del sector público, que puedan decidir sobre el cumplimiento de principios jurídico-públicos como los principios generales de la contratación pública, así como si la adjudicación ha recaído en la oferta económica más ventajosa, sobre la adecuación de los procedimientos contractuales incorporados a las instrucciones, sobre el fondo del contrato ${ }^{59}$, etc.

Esta decisión puede dar lugar a que se produzcan pronunciamientos dispares y contradictorios sobre una misma cuestión. Moreno Molina señala que mientras los litigios sobre la preparación y adjudicación de un contrato de obras con un presupuesto de 5.100.000 de euros serán conocidos por la jurisdicción civil, si el contrato supera los 5.150.000 euros estos mismos actos serán conocidos por la jurisdicción contencioso-administrativa, aunque haya sido dictados por el mismo sujeto contratante. ¿Qué sentido tiene atribuir al orden contencioso-administrativo o al civil el conocimiento sobre contratación pública atendiendo exclusivamente a la cuantía del contrato ${ }^{60}$

Es lógico desde un punto de vista jurídico que los actos preparatorios y la adjudicación de los contratos privados celebrados por las Administraciones públicas se regulen por el Derecho Administrativo y sus controversias se sometan a la jurisdicción contencioso-administrativa. No olvidemos que a través de ellos se seleccionan los contratistas y se adjudica el contrato, con indudable incidencia sobre el derecho fundamental a la igualdad formal y material. Se trata de aplicar la tradicional teoría de los actos separables que tanta utilidad ha proporcionado a los intereses generales. No entendemos por ello el motivo que ha guiado al legislador para atribuir a la jurisdicción civil el conocimiento de los actos de preparación y adjudicación de los contratos celebrados por entes del sector público no considerados Administración pública.

Estamos de acuerdo en que los procedimientos contractuales de estos entes han de estar dotados de mayor flexibilidad y agilidad y permitirles un mayor margen de actuación tanto al órgano de contratación como a los operadores económicos, pero no debemos olvidar que el Derecho comunitario impone la obligación a los Estados miembros de respetar los principios básicos del TCE. Estos principios al estar basados en reglas comunitarias de naturaleza fundacional desempeñan un decisivo papel en la aplicación e interpretación de la normativa contractual pública61. Y esta

59 La jurisdicción contencioso administrativa tiene atribuido el conocimiento de las fases de preparación y adjudicación de los contratos privados sujetos a regulación armonizada celebrados por particulares cuando se trate de contratos subvencionados, y conocerá también de los contratos celebrados por los concesionarios de obras. No entendemos por ello la exclusión del conocimiento por esta jurisdicción de los actos preparatorios y de adjudicación cuando el contrato haya sido celebrado por un ente u organismo público que lleva a cabo actividades de carácter público aunque no quede cubierto por la Directiva comunitaria.

60 La nueva Ley de Contratos del Sector Público, op., cit., p. 191.

61 Baño León, J.M. ${ }^{a}$ (2004), «El contencioso precontractual: las insuficiencias de la tutela jurisdiccional», en Comentarios a la Ley de Contratos de las Administraciones Públicas, Madrid: Cívitas, p.362: More- 
necesidad de interpretación de las normas sobre contratación pública con arreglo a los principios del Tratado, es destacada de forma expresa en el considerando segundo de la Directiva 2004/18/CE ${ }^{62}$.

\section{DISPOSICIONES GENERALES SOBRE LA CONTRATACIÓN DEL SECTOR PÚBLICO}

La LCSP contiene unas disposiciones generales aplicables a la contratación de todos los entes, entidades y organismos del sector público (artículos 22 a 30). Algunas de estas previsiones afectan a nuestro objeto de estudio, por lo que realizaremos un breve recorrido sobre su contenido.

Antes de iniciar el procedimiento encaminado a la adjudicación del contrato los entes, organismos y entidades del sector público no considerados Administraciones públicas deberán tener en cuenta las siguientes previsiones legales:

- Deberán determinar con precisión en la documentación preparatoria del contrato la naturaleza y extensión de las necesidades que pretendan cubrir, así como la idoneidad de su objeto y contenido, ya que no podrán celebrar otros contratos que aquéllos que sean necesarios para el cumplimiento y realización de sus fines institucionales (artículo 22 LCSP).

- Podrán incluir en sus contratos cualquier pacto, cláusula y condición que no sea contrario al interés público, al ordenamiento jurídico y a los principios de buena administración. Y agrupar las prestaciones correspondientes de diferentes contratos en un contrato mixto cuando se encuentren directamente vinculadas entre sí y mantengan relaciones de complementariedad que exijan su consideración y tratamiento como una unidad funcional ${ }^{63}$.

- Salvo que se indique otra cosa, los contratos del sector público se entenderán celebrados en el lugar donde se encuentre la sede del órgano de contratación ${ }^{64}$ y su duración deberá establecerse teniendo en cuenta la naturaleza de las prestaciones

no Molina, J.A. (2008), «¿Por qué una nueva ley de contratos? Objetivos, alcance y principales novedades de la Ley 30/2007, de Contratos del Sector Público", Revista Española de Derecho Administrativo, 139: 440; Gimeno Feliu, J.M. (2008), «Nuevo ámbito subjetivo de aplicación de la Ley de Contratos del Sector Público: luces y sombras», Revista de Administración Pública, 176: 47.

62 Principios de libre circulación de mercancías, libertad de establecimiento y libre prestación de servicios, así como los principios que de estas libertades derivan: principio de igualdad de trato, no discriminación, reconocimiento mutuo, proporcionalidad y transparencia.

63 El artículo 12 LCSP que regula los contratos mixtos determina que cuando un contrato contenga prestaciones correspondientes a otro u otros de distinta clase se atenderá en todo caso, para la determinación de las normas que deban observarse en su adjudicación, al carácter de la prestación que tenga más importancia desde el punto de vista económico.

64 Determinación que resulta fundamental para concretar la jurisdicción competente en caso de conflicto en la ejecución o interpretación del contrato. 
y las características de su financiación ${ }^{65}$. El contrato podrá prever una o varias prórrogas siempre que sus características permanezcan inalterables durante el periodo de duración de éstas y que la concurrencia para su adjudicación haya sido realizada teniendo en cuenta la duración máxima del contrato, incluidos los periodos de prórroga $^{66}$. Los contratos menores no podrán tener una duración superior a un año ni ser objeto de prórroga.

- En relación a los contratos in house providing, los entes, organismos y entidades del sector público que sean considerados medios propios y servicios técnicos (artículos 24.6 y 4 apartado $n$ LCSP), ${ }^{67}$ no podrán participar en la contratación de los poderes adjudicadores de los que sean medios propios, sin perjuicio de que, cuando no concurra ningún licitador, pueda encargárseles la ejecución de la prestación objeto de la encomienda de gestión. No obstante, los contratos que celebren para la realización de las prestaciones objeto de la encomienda quedarán sometidos a la LCSP según la naturaleza de la entidad, el tipo de contrato y la cuantía del mismo, y, en todo caso, cuando se trate de contratos de obra, suministros o servicios cuyas cuantías superen los umbrales comunitarios, las entidades de derecho privado deberán observar para su preparación y adjudicación las reglas establecidas en los artículos 121.1 y 174 LCSP $^{68}$.

— El contenido del contrato deberá necesariamente incluir:

a) La identificación de las partes.

b) La acreditación de la capacidad de los firmantes.

c) La definición del objeto del contrato.

65 Los plazos establecidos por días en la LCSP se entenderán referidos a días naturales, salvo que se haya indicado expresamente que sólo deben computarse los días hábiles. Si el último día del plazo fuera inhábil, éste se entenderá prorrogado al primer día hábil siguiente (Disposición adicional decimoquinta LCSP).

66 Especifica el artículo 23 LCSP que la prórroga se acordará por el órgano de contratación y será obligatoria para el empresario, salvo que el contrato expresamente prevea lo contrario, sin que pueda producirse por el consentimiento tácito de las partes.

67 Se consideran medios propios y servicios técnicos de una entidad pública cuando ésta ostenten sobre ellos un control análogo al que ejerce sobre sus propios servicios. Se entiende que ejercen un control análogo al de sus propios servicios cuando pueda conferirles unilateralmente encomiendas de gestión de obligado cumplimiento y cuya retribución sea fijada por la entidad pública de la que dependan. Esta condición deberá reconocerse expresamente por las normas constitutivas de estos entes y por sus estatutos que deberán precisar también el régimen de las encomiendas que se les pueda conferir. Si se trata de sociedades, la totalidad de su capital ha de ser pública.

68 Véanse Menéndez Menéndez, A. (2008), «La contratación doméstica (in house providing) en la nueva Ley de Contratos del Sector Público», Actualidad Jurídica (Uría \& Menéndez), 21; Pernas García, J. (2008), Operaciones in house y el Derecho comunitario de contratos públicos. Análisis de la jurisprudencia del TJCE, Madrid: Iustel; Meilan Gil, J.L. (2008), La estructura de los contratos públicos. Norma, acto y contrato, Madrid: Iustel; Moreno Molina, J.A. y Pleite Guadañillas, F. (2008), La nueva Ley de Contratos del Sector Público, Madrid: La Ley; Bernal Blay, M.A. (2007), «Un paso en falso en la interpretación del criterio del control análogo al de los propios servicios en las relaciones in house. Comentario de urgencia a la STJCE de 19 de abril de 2007 (As. C-295/05, TRAGSA)", Revista Española de Derecho Administrativo, 137. 
d) La legislación aplicable al contrato.

e) La enumeración de los documentos que integran el contrato ${ }^{69}$.

f) El precio cierto, o el modo de determinarlo ${ }^{70}$.

g) La duración del contrato o las fechas estimadas para el comienzo de su ejecución y para su finalización, así como la prórroga o prórrogas, si estuviesen permitidas.

h) Las condiciones de recepción, entrega o admisión de las prestaciones.

i) Las condiciones de pago.

j) Los supuestos en que procede la resolución.

k) El crédito presupuestario o el programa o rúbrica contable con cargo al que se abonará el precio, en su caso.

I) La extensión del deber de confidencialidad que, en su caso, se imponga al contratista ${ }^{71}$.

- Para determinar el momento de la perfección de estos contratos, el artículo 27 LCSP concreta que los contratos celebrados por las Administraciones públicas y los contratos sujetos a regulación armonizada se perfeccionan mediante la adjudicación definitiva ${ }^{72}$. Por lo que debemos entender que los demás contratos del sector público

69 Esta enumeración podrá estar jerarquizada si así se expresa en el contrato, ordenándose según el orden de prioridad acordado por las partes, en cuyo supuesto, y salvo caso de error manifiesto, el orden pactado se utilizará para determinar la prevalencia respectiva, en caso de que existan contradicciones entre diversos documentos (artículo 26.1 apartado e) de la LCSP)

70 El artículo 75 LCSP, aplicable a todos los contratos del sector público, señala que el precio del contrato deberá ser cierto y podrá formularse tanto en términos de precios unitarios referidos a los distintos componentes de la prestación, como en términos de precios aplicables a tanto alzado a la totalidad o a la parte de las prestaciones del contrato. Excepcionalmente podrán celebrarse contratos con precios provisionales cuando, tras la tramitación de un procedimiento negociado o de un diálogo competitivo, se ponga de manifiesto que la ejecución del contrato debe comenzar antes de que la determinación del precio sea posible por la complejidad de las prestaciones o la necesidad de utilizar una técnica nueva, o que no existe información sobre los costes de prestaciones análogas y sobre los elementos técnicos o contables que permitan negociar con precisión un precio cierto. En estos casos se detallarán en el contrato los extremos que especifica el apartado $5 .^{\circ}$ del artículo 75 LCSP

71 El documento contractual no podrá incluir estipulaciones que establezcan derechos y obligaciones para las partes distintos de los previstos en los pliegos. En el caso de no existir éstos, se deberán concretar en la forma que resulte de la proposición del adjudicatario, o en el acto de adjudicación del contrato de acuerdo con lo actuado en el procedimiento (artículo 26 LCSP).

72 Concreta el artículo 27.1 LCSP que los contratos de las Administraciones Públicas, en todo caso, y los contratos sujetos a regulación armonizada, incluidos los contratos subvencionados a que se refiere el artículo 17, se perfeccionan mediante su adjudicación definitiva, cualquiera que sea el procedimiento seguido para llegar a ella. 
se perfeccionan según las reglas del Derecho privado por el consentimiento de las partes, y desde entonces obligarán, no sólo al cumplimiento de lo expresamente pactado, sino también a todas las consecuencias que, según su naturaleza, sean conformes a la buena fe, al uso y a la ley ${ }^{73}$. A diferencia de lo que acontece con los contratos celebrados por las Administraciones públicas y con los contratos sujetos a regulación armonizada, en los que se distingue entre adjudicación provisional y adjudicación definitiva, perfeccionándose por la adjudicación definitiva (artículos 27 y 135 LCSP), en los contratos no sujetos a regulación armonizada, dicha distinción no tiene aplicación, por lo que tendrán plena validez desde la selección del contratista entendida como acto jurídico único en el que converge el acuerdo de voluntades. No obstante, como el artículo 28 LCSP prohíbe celebrar contratos verbales (salvo que tengan carácter de emergencia $)^{74}$, podemos deducir que los contratos adjudicados por el resto de entidades del sector público se perfeccionan por la firma y formalización del contrato.

- Dejando claro que la exigencia de formalización de los contratos contenida en el artículo 28.2 LCSP y desarrollada posteriormente en el artículo 140 LCSP se circunscribe a los contratos de las Administraciones Públicas, excluyendo de forma expresa a los contratos sujetos a regulación armonizada que celebren los poderes adjudicadores que no sean Administración pública. Dicha exclusión obedece a la exigencia del artículo 140 de que la formalización recaiga en documento administrativo, que sólo podrá ser expedido por las Administraciones públicas ${ }^{75}$. En consecuencia estos entes formalizarán sus contratos en documento privado o, si se estima conveniente, en escritura pública.

- Dentro de los tres meses siguientes a la firma del contrato, los entes del sector público deberán remitir al Tribunal de Cuentas u órgano externo de fiscalización de la Comunidad Autónoma una copia certificada de su formalización, siempre que la cuantía del contrato exceda de 600.000 euros si se trata de obras; 450.000 euros si se trata de suministros y 150.000 si son de servicios. Todo ello sin perjuicio de las facultades del Tribunal de Cuentas o, en su caso, de los correspondientes órganos de fiscalización externos de las Comunidades Autónomas para reclamar cuantos datos, documentos y antecedentes estime pertinentes con relación a los contratos de cualquier naturaleza y cuantía. Por su parte, el Ministerio de Economía y Hacienda mantendrá un Registro de Contratos del Sector Público en el que inscribirán los datos básicos de los contratos adjudicados por las distintas Administraciones Públicas y demás entidades del sector público sujetas a la Ley (artículo 308 y siguientes de la LCSP) ${ }^{76}$. También

73 Artículo 1258 C.c. El artículo 50 del C.co. también remite al contenido de este precepto.

74 Los entes, organismos y entidades del sector público no podrán contratar verbalmente, salvo que el contrato tenga, conforme a lo señalado en el artículo 97.1, carácter de emergencia (artículo 28.1 LCSP).

75 Posibilidad excluida en el caso de entes que, como las sociedades públicas o las fundaciones del sector público tienen naturaleza jurídico-privada. También quedan excluidas las entidades públicas empresariales al no tener la condición de Administración pública a los efectos de la LCSP.

76 Los órganos de contratación de todas las Administraciones Públicas y demás entidades del sector público comunicarán al Registro de Contratos del Sector Público los datos básicos de los contratos 
obliga el artículo 30 de la LCSP a remitir a la Junta Consultiva de Contratación Administrativa determinados datos con fines estadísticos de los contratos celebrados por estos entes.

- Las diferencias y contiendan que puedan surgir sobre los efectos, cumplimiento y extinción de los contratos celebrados por los entes, organismos y entidades del sector público que no tengan el carácter de Administraciones públicas, podrán ser dirimidas mediante arbitraje conforme a las disposiciones de la Ley 60/2003, de 23 de diciembre (artículo 39 LCSP)77. En cambio, nada dice el precepto sobre las cuestiones litigiosas que puedan surgir sobre la preparación y la adjudicación de esos contratos. Queda meridianamente claro que el recurso especial en materia de contratación previsto en el artículo 37 de la LCSP, al tener carácter obligatorio previo a la posterior impugnación en la jurisdicción contencioso-administrativa, deja fuera de su ámbito a los contratos celebrados por los entes del sector público que no son Administración pública, por tener la consideración legal de contratos privados (artículo 20.1 LCSP) y residenciar su conocimiento en la jurisdicción civil (artículo 21.2 LCSP). Excepto los contratos privados sujetos a regulación armonizada en los que sí cabrá la interposición de este recurso especial (artículo 37.1 LCSP) ${ }^{78}$, como trámite previo a la interposición del recurso contencioso -administrativo.

Frente al avance que supone la configuración del recurso especial en materia de contratación pública, existen, no obstante, algunos aspectos que pueden distorsionar su fundamento. El recurso está previsto para determinados actos en el seno de procedimientos sujetos a regulación armonizada, pero no para esos mis-

adjudicados, así como, en su caso, sus modificaciones, prórrogas, variaciones de plazos o de precio, su importe final y extinción. Se constituye así el Registro de Contratos del Sector Público como el sistema oficial central de información sobre la contratación pública en España, y sirve como soporte para su conocimiento, análisis e investigación, para su estadística, para el cumplimiento de las obligaciones internacionales, para la comunicación de los datos a otros órganos de la Administración que estén legítimamente previstas y, en general, para la difusión pública de dicha información, de conformidad con el principio de transparencia.

77 Así lo señala el artículo 39 de la LCSP al especificar que las diferencias que puedan surgir sobre los efectos, cumplimiento y extinción de los contratos que celebren los entes, organismos y entidades del sector público podrán ser remitidas a un arbitraje, conforme a las disposiciones de la Ley 60/2003, de 23 de diciembre.

78 La necesidad de interponer el recurso especial en materia de contratación (artículo 37 LCSP) ante un órgano administrativo como requisito previo a la formulación del recurso contencioso-administrativo, subsana la falta de carácter jurídico-público del sujeto al que imputar el acto recurrido. Véanse Moreno Molina, J.A. (2008), La nueva Ley de Contratos del Sector Público, Madrid: La Ley, p.191; Del Saz Cordero, S. (2007), «La nueva Ley de Contratos del Sector Público. ¿Un mismo traje con las mismas rayas?», Revista de Administración Pública, 174: 349. Del Saz denuncia la paradoja que produce el que las cuestiones que se susciten en relación con los actos de preparación y adjudicación de los contratos armonizados celebrados por entes públicos que no son Administración pública se sometan a los Tribunales del orden contencioso-administrativo, mientras que esos mismos actos, dictados por los mismos órganos, cuando se trata de contratos no sujetos a regulación armonizada, aún cuando estén regulados por la LCSP, escapan de la competencia de la jurisdicción contencioso-administrativa para recaer en los Tribunales ordinarios, que deberán aplicar las determinaciones de la LCSP para este tipo de entidades. 
mos actos adoptados por el mismo sujeto en contratos no sujetos a regulación armonizada. Está claro que el legislador ha pretendido salvaguardar el Derecho comunitario, quedando excluidos los demás contratos que adjudiquen las Administraciones públicas y otros poderes adjudicadores. Lo que nos lleva a preguntarnos: ¿no rigen en nuestro ámbito interno las mismas garantías que proporcionan los principios generales de la contratación pública?; ¿los licitadores de contratos no sujetos a regulación armonizada no están legitimados para resolver sus reclamaciones de manera ágil y eficaz antes de adoptarse la decisión de adjudicar el contrato? La Comunicación Interpretativa de la Comisión Europea de 1 de agosto de 2006, dirigida a los contratos no cubiertos o parcialmente cubiertos por la Directiva 2004/18/CE79, señala que con arreglo a la jurisprudencia del TJCE, las personas deben contar con una protección judicial efectiva para hacer valer los derechos que les confiere el ordenamiento jurídico comunitario, por lo que aconseja la existencia de recursos rápidos resueltos por autoridades independientes al margen del importe del contrato.

Otro aspecto cuestionable del recurso especial es el carácter obligatorio previo a la jurisdicción contencioso-administrativa, configurándolo como preclusivo, de manera que si no se interpone el mencionado recurso los actos objeto de impugnación no serán susceptibles de recurso contencioso-administrativo en vía jurisdiccional ${ }^{80}$. También nos llama la atención que el órgano competente para resolver el recurso en los contratos celebrados por las Administraciones públicas sea al mismo tiempo el órgano de contratación, por el riesgo que la decisión adoptada pueda suponer para el principio de objetividad ${ }^{81}$. En el caso de los contratos celebrados por entes distintos a las Administraciones públicas, la Ley contempla al titular del departamento al que esté adscrita la entidad contratante o al que corresponda su tutela como órgano competente para resolver (artículo 37.4 LCSP).

79 Comunicación de la Comisión Europea de 1 de agosto de 2006, 2006/C179/02, que interpreta y sistematiza la jurisprudencia del TJCE en materia de contratación pública y propone las mejores prácticas para obtener el máximo beneficio del mercado interior.

80 Otra característica es el breve plazo para su interposición (diez días), con diferentes reglas, según el acto recurrido, para determinar el dies ad quem que iniciará el cómputo del plazo. En el caso de que el acto recurrido sea la adjudicación provisional, que deberá ser notificada a todos los licitadores (artículo 135 LCSP), el plazo se contará desde el día siguiente a la publicación de la misma en el perfil del contratante y no desde la fecha de la recepción de la notificación.

81 En cuanto al sistema de recursos contra los actos adoptados en el curso de un procedimiento contractual no sujeto a regulación armonizada, no existe en la LCSP previsión alguna respecto del régimen de recursos aplicable. De manera que si el contrato ha sido celebrado por una Administración pública le será aplicable el régimen ordinario de recursos administrativos de conformidad con la Ley 30/1992 y la LJCA. El problema surge al no ser equiparable el sistema general de recursos administrativos con las previsiones de la LCSP. Con la actual regulación, la elevación a definitiva de la adjudicación provisional (diez días transcurridos los quince de publicidad), se llevará a efecto con independencia de la interposición de los recursos, ya que estos no tienen efecto suspensivo inmediato. Por todo ello, ni los plazos de interposición, ni de resolución, ni los efectos de la interposición del recurso administrativo parecen 62 de la adjudicación provisional. 


\section{PARTES, OBJETO, PRECIO Y GARANTÍAS PARA CONTRATAR}

\section{Partes del contrato}

\section{A) Entidad Contratante}

La competencia para contratar en las entidades públicas empresariales, si no existe disposición específica en sus correspondientes normas de creación, corresponderá a los presidentes o directores ${ }^{82}$. Respecto de las sociedades y fundaciones públicas, la capacidad para contratar se regirá por lo dispuesto en sus estatutos y por las normas de Derecho privado que sean en cada caso de aplicación.

Esta competencia podrá ser delegada o desconcentrada con las formalidades aplicables en cada caso si se trata de órganos administrativos, y mediante el otorgamiento de poderes si se trata de sociedades o fundaciones ${ }^{83}$.

Distinta de la figura del órgano de contratación, como órgano capaz de obligarse en nombre de la institución, LCSP contempla la figura del responsable del contrato a quien corresponde supervisar su ejecución, adoptar las decisiones y dictar las instrucciones necesarias con el fin de asegurar la correcta realización de la prestación pactada, dentro de las facultades que el órgano de contratación le haya atribuido ${ }^{84}$.

Aunque no es una exigencia legal, sí es aconsejable que en los contratos sujetos a regulación armonizada el órgano de contratación se encuentre asistido de un órgano de valoración que se encargue de calificar la documentación presentada y elevar una propuesta de adjudicación ${ }^{85}$. En los procedimientos en los que exista Mesa de Contratación, corresponderá a ésta la valoración de las ofertas, pudiendo solicitar los

82 Especifica el artículo 291.2 LCSP para el ámbito estatal, que los presidentes o directores de las entidades públicas empresariales y demás entidades estatales serán los órganos de contratación a falta de disposición específica sobre el particular. Y podrán constituirse Juntas de Contratación que actuarán como órganos de contratación, con los límites cuantitativos o referentes a las características de los contratos que determine el titular del departamento, en los casos que concreta su apartado $4 .^{\circ}$

83 El otorgamiento de poderes a favor del presidente, director o gerente de la entidad u organismo público es una práctica muy habitual. Requiere el acuerdo válidamente adoptado por el patronato, consejo de dirección o de administración, y deberá elevarse a documento público.

84 Al tratarse los contratos objeto de nuestro estudio de contratos privados su ejecución queda fuera del ámbito de aplicación de la LCSP. El responsable del contrato podrá ser una persona física o jurídica, vinculada al ente, organismo o entidad contratante o ajena a él (artículo 41 LCSP). No queda claro en la LCSP si el responsable del contrato lo será para cada uno de los contratos celebrados o para un número indeterminado de ellos. Tampoco especifica la Ley cómo deberá formalizarse su nombramiento o designación.

85 La exigencia de Mesa de Contratación en los procedimientos abiertos, restringidos y negociados con publicidad y las normas sobre su composición y nombramiento resultan aplicables a los contratos celebrados por las Administraciones públicas (artículo 295 LCSP). No obstante, para una adecuada garantía de los principios de objetividad y transparencia en la selección de la oferta económicamente más ventajosa, la mayoría de las instrucciones aprobadas por las entidades y organismos públicos que hemos podido consultar contemplan la asistencia de la Mesa de Contratación para los contratos adjudicados por poderes adjudicadores. 
informes técnicos que estime necesarios. En los concursos de proyectos, la Mesa de Contratación se constituirá en jurado, incorporando a su composición ${ }^{86}$ personalidades de notoria competencia que puedan contribuir de forma especial en la evaluación de las propuestas presentadas, y participar en las deliberaciones con voz y voto. Los miembros del jurado deben ser personas físicas independientes de los participantes del concurso de proyectos.

La información relativa a las licitaciones y adjudicaciones de los contratos del sector público se difundirá a través de Internet mediante el perfil de contratante del órgano de contratación (artículo 42 LCSP) ${ }^{87}$. Su acceso deberá especificarse en las páginas web institucionales, en la Plataforma de Contratación del Estado, en los pliegos y en los anuncios de licitación. Se entenderán cumplidas las exigencias derivadas del principio de publicidad con la inserción de la información relativa a la licitación de los contratos cuyo importe supere los 50.000 euros en el perfil de contratante. En este medio se publicará también la adjudicación de los contratos, salvo los contratos menores y los adjudicados por procedimiento negociado. No obstante las licitaciones y adjudicaciones de los contratos sujetos a regulación armonizada deberán publicarse en el DOUE e insertar su información en la Plataforma de Contratación ${ }^{88}$ o en el sistema equivalente gestionado por la Administración pública de la que dependa la entidad contratante.

\section{B) Contratista}

Podrán contratar con los entes del sector público las personas naturales o jurídicas, españolas o extranjeras, que tengan plena capacidad de obrar (según lo establecido en el artículo 61 LCSP), no estén incursas en una prohibición de contratar $^{89}$ y

86 La composición de la Mesa de Contratación será la prevista en los pliegos de condiciones particulares. De forma orientativa contarán: a) de un presidente, en nuestro caso, un consejero delegado o un director gerente; b) de 2 vocales, uno de la asesoría jurídica para las cuestiones de legalidad que pueda plantear el expediente, y otro, un vocal técnico, en función de la materia o del área que promueva el contrato; c) de un secretario, con voz pero sin voto, que se ocupará de las relaciones que surjan con los licitadores y de tramitar el concreto expediente de contratación

87 Establece el artículo 42 LCSP que con el fin de asegurar la transparencia y el acceso público a la información relativa a su actividad contractual, y sin perjuicio de utilizar otros medios de publicidad en los casos legalmente previstos, los órganos de contratación difundirán, a través de Internet, su perfil de contratante.

88 La Junta Consultiva de Contratación Administrativa del Estado pone a disposición de todos los órganos de contratación del sector público una plataforma electrónica que permita dar publicidad a través de Internet de las convocatorias de licitaciones y sus resultados, y de cuanta información considere relevante relativa a la contratación pública (artículo 309 LCSP).

89 El apartado $1 .^{\circ}$ del artículo 49 LCSP enumera una serie de prohibiciones para contratar con «todo el sector público», y el apartado $2^{\circ}$, añade otras que, adicionalmente, se aplicarán sólo a la contratación de las Administraciones públicas. En consecuencia, los sujetos del sector público no considerados Administraciones públicas, deberán exigir en su contratación el cumplimiento de las prohibiciones de contratar del artículo 49.1 LCSP, siendo también de aplicación el artículo 62, relativo a la acreditación o prueba de la no concurrencia de una prohibición de contratar por parte de los empresarios. Llama la atención que no se les aplique a estos entes la prohibición cuando el contratista haya sido sancionado en materia fiscal o de 64 subvenciones. Véase Sosa Wagner, F. y Fuertes López, M. (2008), «La Ley de Contratos del Sector Público y el murciélago", Actualidad Jurídica Aranzadi, 743. 
acrediten la solvencia económica, financiera, técnica y profesional que determine el órgano de contratación para cada contrato ${ }^{90}$. Las personas físicas o jurídicas de Estados no pertenecientes a la Unión Europea contratarán de acuerdo a lo establecido en el artículo 44 LCSP, las empresas comunitarias, de conformidad con lo dispuesto en el artículo 47 LCSP y, las uniones temporales de empresas, atenderán a las exigencias del artículo 48 LCSP. No podrán concurrir a los procedimientos de adjudicación las empresas que hubieran participado en la elaboración de las especificaciones técnicas o de los documentos preparatorios del contrato, cuando dicha participación pueda provocar restricciones a la libre concurrencia o suponer un trato privilegiado respecto del resto de las empresas licitadoras.

Los empresarios además de la capacidad de obrar, deberán acreditar estar en posesión de las condiciones mínimas de solvencia económica, financiera, técnica y profesional que se determinen por el órgano de contratación ${ }^{91}$. Se podrá acreditar la solvencia mediante medios externos, que pueden ser de otras entidades independientemente de la naturaleza jurídica de los vínculos que tengan entre sí, siempre que demuestren que, para la ejecución del contrato, disponen efectivamente de esos medios. Este requisito podrá ser sustituido por una determinada clasificación cuando así se establezca en los pliegos de condiciones particulares. Ya que las exigencias legales sobre clasificación de empresas, son potestativas para los entes del sector público no considerados Administraciones Públicas, que podrán exigirlas si lo estiman oportuno ${ }^{92}$. La inscripción del empresario en el Registro Oficial de Licitadores acreditará frente a todos los órganos de contratación del sector público su aptitud para contratar, su personalidad, la capacidad de obrar, la solvencia económica, financiera, técnica y profesional, así como la concurrencia o no de prohibiciones para contratar.

Sin olvidar para los contratos sujetos a regulación armonizada las previsiones de los artículos 69 y 70 LCSP sobre la acreditación del cumplimiento de las normas de garantía de la calidad y de las normas de gestión medioambiental.

90 En relación a la capacidad o aptitud del contratista (artículos 43 a 73 LCSP), a los contratos celebrados por entes públicos no considerados Administraciones públicas, les son de aplicación las condiciones generales de aptitud del artículo 43; el contenido del artículo 44 dedicado a las empresas no comunitarias; las condiciones especiales de compatibilidad del artículo 45; las normas especiales sobre capacidad (artículos 46 a 48); las prohibiciones para contratar del artículo 49.1, y las condiciones de solvencia (artículos 51 a 53). Para los contratos no sujetos a regulación armonizada, los medios para acreditar la solvencia no tendrán que ser los exigidos por los artículos 64 a 68. Tampoco serán de aplicación los artículos 54 a 60 relativos a la clasificación de empresas, cuya regulación está destinada exclusivamente a los contratos administrativos, ya que inician su regulación especificando que «para contratar con las Administraciones Públicas (... ) será requisito indispensable que el empresario se encuentre debidamente clasificado».

91 Los criterios exigidos sobre la solvencia de las empresas deberán figurar en el anuncio de licitación y se especificarán en el pliego del contrato, debiendo estar vinculados al objeto del contrato y ser proporcionales al mismo (artículo 51 LCSP).

92 Los certificados de clasificación que acrediten la inscripción en listas oficiales de empresarios autorizados para contratar establecidas por los Estados miembros de la Unión Europea, sientan una presunción de aptitud en relación a las cuestiones a que se refiere el artículo 73 LCSP. 


\section{Objeto, precio y cuantía del contrato ${ }^{93}$}

Establece la LCSP que los contratos tendrán un objeto determinado y un precio cierto. No podrá fraccionarse el objeto de un contrato con la finalidad de disminuir su cuantía y eludir así los requisitos de publicidad o los relativos al procedimiento de adjudicación que le corresponda. Cuando el objeto del contrato admita fraccionamiento y se justifique debidamente en el expediente, podrá dividirse en lotes o fases de ejecución independientes, siempre que sean susceptibles de utilización separada y constituyan una unidad funcional. También se podrá contratar separadamente prestaciones diferenciadas que se integren en una misma obra y requieran una determinada habilitación. Las normas procedimentales y de publicidad para la adjudicación de cada lote o prestación diferenciada se determinarán en función del valor acumulado del conjunto, salvo lo dispuesto en los artículos 14.2, 15.2 y 16.2 LCSP94.

La retribución del contratista consistirá en un precio cierto expresado en euros cuyo pago se realizará en la forma que terminen los pliegos. Los contratos podrán incluir cláusulas de variación de precios en función del cumplimiento de determinados objetivos de plazos o rendimiento, así como penalizaciones por incumplimiento de cláusulas contractuales, debiendo determinar con precisión los supuestos en que se producirán estas variaciones y las reglas para su determinación. El hecho de que el artículo 75.7 LCSP prohíba expresamente el pago aplazado en los contratos de las Administraciones públicas, abre la posibilidad a los contratos celebrados por el resto de entidades del sector público. No rige tampoco para la contratación de estos entes los criterios para apreciar los valores anormales o desproporcionados ${ }^{95}$.

El valor estimado de los contratos vendrá determinado por el importe total, sin incluir el impuesto sobre el valor añadido ${ }^{96}$. En el cálculo del importe total estimado, deberán tenerse en cuenta las eventuales prórrogas del contrato. Cuando se haya previsto abonar primas o efectuar pagos a los licitadores, la cuantía de los mismos se tendrá en cuenta en el cálculo del valor estimado del contrato. La estimación deberá hacerse teniendo en cuenta los precios habituales en el mercado, y el resto de reglas establecidas en el artículo 76 de la LCSP.

93 Las normas generales relativas al objeto, precio y cuantía del contrato (artículos 74 a 76 LCSP) son aplicables a todo el sector público.

94 Cuando se fraccione el objeto del contrato, las normas a aplicar se determinarán en función del valor acumulado del conjunto, salvo que en el contrato de obra el valor estimado de los lotes sea inferior a un millón de euros y el importe acumulado de los mismos no sobrepase el $20 \%$ del valor acumulado de la totalidad (artículo 14.2 LCSP). En el contrato de suministro y en el de servicios cuando el valor acumulado de los lotes sea inferior a 80.000 euros, con la misma limitación (artículos 15.2 y 16.2 LCSP respectivamente).

95 Por expresa indicación del artículo 174.1 LCSP, los criterios para apreciar el carácter normal o desproporcionado de las ofertas que establecen los apartados 1 y 2 del artículo 136, no son de aplicación a los contratos sujetos a regulación armonizada que celebren los poderes adjudicadores que no sean Administración pública.

96 El precio podrá formularse en términos de precios unitarios según las unidades o componentes del contrato o a tanto alzado para la totalidad o el conjunto de las prestaciones. También permite la Ley los precios provisionales que deberán establecerse teniendo en cuenta los beneficios del contratista y los costes en que se pueda incurrir. 
Los mecanismos de la revisión de precios tienen como destinatarios exclusivos los contratos de las Administraciones públicas, por lo que debemos entender que la libertad de pactos será la que rija los sistemas de revisión aplicables a los contratos del resto de entidades del sector público, que en cualquier caso, deben quedar establecidos en el pliego de cláusulas administrativas particulares o en el propio texto del contrato.

\section{Garantías exigibles en la contratación del sector público}

Doble regulación contiene la LCSP sobre las garantías exigibles a los contratistas. Para los contratos administrativos los artículos 83 a 91 establecen una regulación detallada y extensa. Para los demás contratos del sector público, el artículo 92 admite la constitución de garantías como una facultad potestativa del órgano de contratación, que podrá exigir una garantía a los licitadores para responder del mantenimiento de las ofertas hasta la adjudicación provisional (garantía provisional), o para asegurar la correcta ejecución de del contrato (garantía definitiva). Este carácter potestativo de las garantías permite al órgano de contratación, al amparo del principio de libertad de pactos, optar por aplicar las reglas que establece la LCSP, o aplicar un régimen distinto. En el primer supuesto, no será de aplicación el artículo 89 LCSP sobre preferencia en la ejecución de las garantías, al tratarse de una prerrogativa de la Administración pública que no puede extenderse a otros sujetos. El importe de la garantía, que podrá prestarse en alguna de las formas previstas en el artículo 8497, así como el régimen de su devolución o cancelación serán establecidos por el órgano de contratación, atendidas las circunstancias y características del contrato.

\section{PREPARACIÓN Y ADJUDICACIÓN DE LOS CONTRATOS CELEBRADOS POR «PODERES ADJUDICADORES»}

\section{Preparación del contrato}

Como hemos visto anteriormente, los contratos celebrados por poderes adjudicadores que no tengan el carácter de Administración pública iniciarán su andadura con un informe que determine la naturaleza y extensión de las necesidades a cubrir, la idoneidad de su objeto, el coste aproximado, la existencia de presupuesto suficiente, el tipo de procedimiento propuesto y la modalidad de su publicidad. El artículo 121 $\mathrm{LCSP}^{98}$ concreta los actos preparatorios distinguiendo dos regímenes:

a) Uno aplicable a los contratos sujetos a regulación armonizada; a los contratos de servicios de cuantía igual o superior a 206.000 euros, comprendidos

97 En cualquier caso, sea cual sea el modelo elegido por el órgano de contratación, las garantías deberán presentarse en alguna de las formas previstas en el artículo 84 LCSP. No obstante, no será obligatorio en el caso de que la garantía se preste en metálico que se deposite en la Caja General de Depósitos.

98 Dedicado a las reglas aplicables a la preparación de los contratos celebrados por poderes adjudicadores que no tengan el carácter de Administraciones públicas. 
en las categorías 17 a 27 del Anexo II99; y a los contratos subvencionados a que se refiere el artículo 17 LCSP (apartado $1 .^{\circ}$ artículo 121 LCSP).

b) El segundo prevé determinadas reglas para contratos distintos a los anteriores de cuantía superior a 50.000 euros (apartado $2 .^{\circ}$ artículo 121 LCSP).

a) Los contratos a que se refiere el apartado $10^{\circ}$ del artículo 121 LCSP, en sus actos preparatorios deberán observar las reglas relativas a la definición y establecimiento de prescripciones técnicas que señala el artículo 101 LCSP; las relativas a las condiciones especiales de ejecución que especifica el artículo 102 LCSP; deberán transmitir la información relativa a las obligaciones fiscales, de protección del medio ambiente, empleo y condiciones laborables (artículo 103 LCSP), así como sobre las condiciones de subrogación en los contratos de trabajo (artículo 104 LCSP). Si el contrato pretende atender una necesidad inaplazable o si resulta preciso acelerar la adjudicación por razones de interés público, el órgano de contratación podrá declarar urgente su tramitación, motivándolo debidamente en la documentación preparatoria. En este caso se podrán reducir los plazos ${ }^{100}$.

b) En contratos distintos a los anteriormente mencionados de cuantía superior a 50.000 euros (artículo 121 apartado 2. ${ }^{\circ}$ LCSP), los poderes adjudicadores que no tengan el carácter de Administraciones Públicas deberán elaborar un pliego, en el que se establezcan las siguientes cuestiones ${ }^{101}$ :

- Las características básicas del contrato.

— El régimen de admisión de variantes.

— Las modalidades de recepción de las ofertas.

— Los criterios de adjudicación.

99 Las categorías 17 a 27 del Anexo II se refiere a los siguientes servicios: hostelería y restaurante; transporte y ferrocarril; transporte fluvial y marítimo; transportes complementarios y auxiliares; servicios jurídicos; de colocación y suministro de personal; de investigación y seguridad, excepto servicios de furgones blindados; educación y formación profesional; servicios sociales y de salud; de esparcimiento, culturales y deportivos.

100 Los expedientes correspondientes a los contratos cuya celebración responda a una necesidad inaplazable, o cuya adjudicación sea preciso acelerar por razones de interés público, podrán ser objeto de tramitación urgente (artículo 96 LCSP). A tales efectos el expediente deberá contener la declaración de urgencia del órgano de contratación debidamente motivada. La tramitación de urgencia permitirá reducir los plazos establecidos a la mitad, así como iniciar la ejecución del contrato sin previa formalización del mismo.

101 Los actos de preparación de los contratos de cuantía inferior a 50.000 euros, celebrados por poderes adjudicadores que no tengan el carácter de Administraciones públicas quedan sin previsiones legales específicas. Se podría argumentar que la razón de ser de esta exclusión la podemos encontrar en la coincidencia de está cuantía con la admitida para el contrato menor de obras (122 LCSP). Sin embargo, no sucede así con los contratos menores de servicios y de suministro, para los que el artículo 122.3 LCSP prevé la cuantía de 18.000 euros. Por ello, cabe plantearse ¿qué ocurrirá con los actos preparatorios de los contratos que superen dicha cuantía? Consideramos que hubiera sido deseable el establecimiento de unas condiciones mínimas. 
- Las garantías que puedan constituirse por el licitador y el adjudicatario.

- La información sobre las condiciones de subrogación en los contratos de trabajo.

El pliego de condiciones particulares recogerá los requisitos exigidos para licitar y los pactos y condiciones definitorias de los derechos y obligaciones que asumirán las partes del contrato. Deberá ser aprobado mediante resolución motivada antes de la apertura del procedimiento de adjudicación. En el expediente se justificará adecuadamente la elección del procedimiento y de los criterios para adjudicar el contrato.

\section{Adjudicación del contrato}

La adjudicación de contratos celebrados por poderes adjudicadores que no tengan la consideración de Administración pública se llevará a cabo de acuerdo con los artículos 174 y 175 LCSP que prevé también dos regímenes jurídicos distintos:

a) Adjudicación de contratos sujetos a regulación armonizada y contratos subvencionados (artículo 174 LCSP).

b) Adjudicación de contratos no sujetos a regulación armonizada (artículo 175 LCSP).

En el primer caso, contratos sujetos a regulación armonizada (artículo 174 LCSP), las normas aplicables son las mismas que las contempladas para las Administraciones públicas con las siguientes adaptaciones:

a) Se mantiene la obligación de publicar las licitaciones y adjudicaciones en el DOUE, pero se les exime de su publicación en los diarios oficiales internos que se sustituye por la inserción de la correspondiente información en la Plataforma de Contratación a que se refiere el artículo 309, o en el sistema equivalente gestionado por la Administración pública de la que dependa la entidad contratante.

b) No serán de aplicación las reglas relativas a la intervención del comité de expertos para valorar los criterios subjetivos que se hayan establecido para baremar las ofertas (artículo 134.2); ni las relativas a la apreciación de las ofertas anormales o desproporcionadas (artículo 136.1 y 2); tampoco las previstas en el artículo 140 para la formalización del contrato; ni las formuladas para el examen de las proposiciones y propuesta de adjudicación (artículo 144). Y, finalmente, tampoco les resulta de aplicación los supuestos en los que es posible acudir al procedimiento negociado en el caso de gestión de servicios públicos ${ }^{102}$.

102 En cuanto a la última exclusión, la referida al artículo 156 LCSP sobre el procedimiento negociado de los contratos de gestión de servicios públicos, quizá estemos ante un error de redacción del 
De todo ello podemos deducir que estos contratos se adjudicarán a través de los procedimientos establecidos en la Ley para las Administraciones públicas:

- Procedimientos ordinarios: abierto y restringido.

- Procedimientos especiales o excepcionales: diálogo competitivo y procedimiento negociado.

Los medios de racionalización técnica de la contratación: acuerdos marco, sistemas dinámicos de contratación y centrales de contratación, previstos para la contratación de las Administraciones públicas (artículo 178 LCSP), podrán ser utilizados también para la adjudicación de contratos sujetos a regulación armonizada celebrados por otras entidades del sector público (artículo 179 LCSP).

En cuanto a los contratos celebrado por poderes adjudicadores no sujetos a regulación armonizada (artículo 175 LCSP), las exigencias son infinitamente menores, pues los procedimientos reglados de licitación son sustituidos por la aplicación de los principios de publicidad, concurrencia, transparencia, confidencialidad, igualdad y no discriminación. Mientras que los procedimientos de adjudicación se sustituyen por unas instrucciones internas de obligado cumplimiento en las que se deberán especificar la forma de hacer efectivos los mencionados principios y que el contrato es adjudicado a la oferta económicamente más ventajosa ${ }^{103}$. Estas instrucciones ${ }^{104}$ deben ponerse a disposición de los interesados y publicarse en el perfil de contratante de la entidad u organismo. El principio de publicidad se da por cumplido con la publicación en el perfil del contratante de las licitaciones de contratos superiores a 50.000 euros $^{105}$, sin perjui-

legislador o ante una contradicción legal. El artículo 8 LCSP de forma expresa reserva el contrato de gestión de servicio público para ser celebrado exclusivamente por las Administraciones públicas: «el contrato de gestión de servicios públicos es aquél en cuya virtud una Administración Pública encomienda a una persona, natural o jurídica, la gestión de un servicio cuya prestación ha sido asumida como propia de su competencia por la Administración encomendante». Sin embargo, el artículo 174 LCSP, también de forma expresa se refiere a los contratos sujetos a regulación armonizada celebrados por poderes adjudicadores que no tengan el carácter de Administración pública.

103 Este concepto jurídico indeterminado: oferta económica más ventajosa, supone que no se adjudicará el contrato a la oferta cuyo precio sea el más bajo, sino que se tendrá en cuenta la oferta que en su conjunto resulte más adecuada a los intereses generales. El artículo 134 establece una serie de criterios para la valoración de las proposiciones. Sólo en el caso de que se utilice un único criterio de adjudicación, será necesariamente el del precio más bajo.

104 En el ámbito del sector público estatal, la aprobación de las instrucciones requerirá el informe previo de la Abogacía del Estado. Véase la Instrucción de la Abogacía General del Estado 1/2008, de 5 de febrero, sobre contratación de las fundaciones del sector público estatal, sociedades mercantiles del Estado y entidades públicas empresariales dependientes de la Administración General del Estado.

105 Nada dice la Ley sobre la publicidad de las adjudicaciones de estos contratos. El artículo 138 LCSP que regula la publicidad de las adjudicaciones está incluido en el capítulo dedicado a la adjudicación de los contratos de las Administraciones públicas, y el artículo 175 LCSP, precepto específico de las adjudicación de poderes adjudicadores que no tienen el carácter de Administración pública, se refiere exclusivamente a la publicidad de las licitaciones, aunque el mismo precepto arranca su regulación con el sometimiento de las adjudicaciones al principio de publicidad. También el artículo 42 LCSP, al regula la información que deberá incluir el perfil de contratante, especifica que «en todo caso deberá publicarse en 70 el perfil de contratante la adjudicación provisional de los contratos». 
cio de que las instrucciones puedan arbitrar otras modalidades, alternativas o adicionales, de difusión ${ }^{106}$.

¿Qué pasará con los contratos cuyo importe se encuentra por debajo de esa cifra? Al no mencionarlos el artículo 175 LCSP, cabe deducir que el órgano de contratación tiene plena libertad para regular la adjudicación en su normativa interna. La Comunicación Interpretativa de la Comisión sobre el Derecho comunitario aplicable en la adjudicación de contratos no sujetos a las Directivas de contratación pública ${ }^{107}$, recomienda que se valore caso por caso la incidencia que el contrato puede tener en el mercado interior, puesto que la licitación ${ }^{108}$ queda sometida a los principios generales que emanan del TCE ${ }^{109}$, aunque el contrato no esté sujeto a regulación armonizada ${ }^{10}$. Así lo señala expresamente el Auto del TJCE de 3 de diciembre de 2001, al determinar que «aunque algunos contratos estén excluidos del ámbito de aplicación de las Directivas comunitarias, las entidades adjudicadoras que los celebren están obligadas a respetar las normas fundamentales del TCE, en concreto, los principios de objetividad, imparcialidad y no discriminación en la adjudicación de sus contratos públicos»»11.

En este sentido, la Instrucción de la Abogacía General del Estado 1/2008, de 5 de febrero ${ }^{12}$, hace las siguientes consideraciones:

106 Ello supone recurrir a alguno de los procedimientos que impliquen publicidad. Se podrá utilizar el procedimiento abierto como procedimiento base de la contratación, el procedimiento restringido y el procedimiento negociado con publicidad en ocasiones muy concretas. En algunas de las instrucciones internas aprobadas por sociedades mercantiles públicas que hemos tenido la oportunidad de consultar, se recoge de manera expresa que «los contratos no sujetos a regulación armonizada podrán adjudicarse mediante procedimiento negociado cuando concurran las circunstancias generales previstas en el artículo 154 LCSP, y las específicas para los contratos de obras y de servicios y suministros, previstas en los artículo 155, 157 y 158 LCSP» (Instrucciones internas de contratación de Ciudad Del Motor de Aragón S.A).

107 Comunicación Interpretativa de la Comisión Europea de 1 de agosto de 2006, 2006/C179/02, que interpreta y sistematiza la jurisprudencia del TJCE en materia de contratación pública y propone las mejores prácticas para obtener el máximo beneficio del mercado interior.

108 Que deberá ser suficientemente anunciada en el perfil de contratante, boletines oficiales nacionales, boletines especializados o publicaciones locales, DOUE, etc. Ninguno de estos medios es obligatorio, aunque la ausencia de publicidad por cualquiera de ellos llevaría al incumplimiento de los principios de contratación pública y, en consecuencia, a la infracción del Derecho comunitario, salvo que se tratara de un procedimiento negociado sin publicidad admitido en las Directivas.

109 Las libertades fundamentales del TCE que obligan a los Estados miembros como la libre circulación de mercancías, el derecho de establecimiento y la libre prestación de servicios en su aplicación conllevan el respeto al principio de publicidad, igualdad de trato, reconocimiento mutuo, proporcionalidad, transparencia y no discriminación. Sobre la obligación de respetar los principios generales del Derecho comunitario en los contratos no sujetos a las Directivas comunitarias, puede verse la STJCE de 14 de junio de 2007, Medipac-Karantzidis A y Venizeleio-Pananeio; El Auto del TJCE de 3 de diciembre de 2001, C-59/00; y la STJCE de 7 de diciembre de 2000, C-324/1998, que sirvió de fundamento al Auto anterior.

110 En cuyo ámbito se comprenden dos grandes grupos de contratos: aquellos cuyo importe sea inferior a los umbrales de aplicación del Derecho comunitario, o cuyos órganos de contratación no tengan la consideración de poderes adjudicadores según el artículo 1.9 de la Directiva 2004/18/CE.

111 Auto del TJCE de 3 de diciembre de 2001, Asunto C-59/00. Véase también la STJCE de 13 de octubre de 2005, asunto C-458/03, Parking Brixen GMBH.

112 «Sobre la contratación de las fundaciones del sector público estatal, sociedades mercantiles del Estado y entidades públicas empresariales dependientes de la Administración General del Estado». Abogacía General del Estado. Ministerio de Justicia. 
1. $\quad$ En los contratos de cuantía superior a 50.000 euros, el requisito de la publicidad se entiende cumplido con la inserción de la información en el perfil del contratante, sin perjuicio de que este medio de publicidad pueda ir acompañado de otras modalidades de difusión o ser sustituido por éstas.

2. ${ }^{\text {a }}$ En los contratos de cuantía inferior a 50.000 euros, el requisito de la publicidad es también exigible pero al no indicarse el medio, cabe entender que su determinación se remite a la consideración de la entidad contratante que deberá utilizar un medio de publicidad proporcionado a la cuantía del contrato, a su objeto, características particulares, localización geográfica, etcétera.

La remisión del artículo 175 LCSP a las instrucciones internas que deberán aprobar los poderes adjudicadores para hacer efectivos los principios generales de contratación pública, supone un desplazamiento del núcleo esencial de la contratación pública, a pesar de que la LCSP reconoce que su objetivo y razón de ser es «regular toda la contratación del sector público» (artículo 1) ${ }^{113}$. Esta deslegalización procedimental mediante instrucciones, puede producir dispersión y fragmentación del mercado debido a la amplia y variada gama de procedimientos que se implantarán generando barreras de entrada para nuevos operadores económicos ${ }^{144}$, y dificultando el conocimiento para los contratistas interesados ${ }^{115}$. Además de que el grado de su cumplimiento dependerá de la exclusiva voluntad de los poderes adjudicadores.

\section{PREPARACIÓN Y ADJUDICACIÓN DE LOS CONTRATOS CELEBRADOS POR ENTIDADES NO CONSIDERADAS PODERES ADJUDICADORES NI ADMINISTRACIONES PÚBLICAS. «DEMÁS ENTES DEL SECTOR PÚBLICO»}

A la contratación de estas entidades no se les aplica la distinción entre contratos sujetos a regulación armonizada y los no sujetos, al quedar fuera del ámbito de aplicación de la Directiva 2004/18/CE ${ }^{116}$ y de la mayoría de las previsiones de la

113 Con el objetivo de garantizar que la misma se ajusta a los principios de libertad de acceso a las licitaciones, publicidad y transparencia de los procedimientos, no discriminación e igualdad de trato...

114 Véase la Circular 1/08 de la Junta Consultiva de Contratación Administrativa de Aragón interpretativa de la Ley de Contratos del Sector Público, donde se especifica que ante la situación que pueden crear las innumerables y variadas instrucciones internas de contratación, la Junta Consultiva traslada al Gobierno la conveniencia de que se adopten medidas normativas que puedan corregir las disfunciones a fin de garantizar la eficacia, concurrencia y eficiencia de los fondos públicos.

115 Gimeno Feliu J.M. (2008), «El nuevo ámbito subjetivo de aplicación de la Ley de Contratos del Sector Público: luces y sombras», op., cit., p. 50. Considera que hubiera sido mejor introducir cierta flexibilización en los procedimientos de forma uniforme. Preguntándose por la naturaleza jurídica de estas instrucciones y por su control. Sobre este tema consúltese también a González García, J. (2008), Sociedades estatales de obras públicas, Valencia: Tirant lo Blanch, p. 158.

116 Por la simple razón de que estos organismos y entidades no están incluidos en el concepto comunitario de organismo de derecho público que utiliza la Directiva 2004/18/CE en su ámbito subjetivo de aplicación (artículo 1.9). Bien porque han sido creados para satisfacer necesidades de interés general que 
LCSP ${ }^{117}$. No obstante, quedará sujeta a las normas generales que la LCSP establece para todos los contratos del sector público. En concreto a las siguientes reglas:

- Las relativas a la justificación de necesidad e idoneidad del contrato (artículo 22).

— Los criterios generales para determinar su duración (artículo 23).

— Las reglas sobre el contenido mínimo del contrato (artículo 25).

— Sobre el carácter formal de la contratación (artículo 28).

— La obligación de información al Tribunal de Cuentas (artículo 29).

- El perfil de contratante (artículo 42).

- Algunas reglas relativas a la capacidad y prohibiciones de contratar (artículos 43 a 49.1 y 50$)$.

- Las referidas al objeto, precio y cuantía del contrato (artículos 74 a 76).

En cuanto a la adjudicación de sus contratos, el 176 LCSP contiene unas previsiones muy similares a las contempladas por la disposición adicional sexta del TRLCAP ${ }^{118}$, al exigirles el cumplimiento de los principios generales de contratación pública. Incorporando la necesidad de que el contrato sea adjudicado a la oferta económicamente más ventajosa. La concreción de ambas obligaciones quedará incluida en las instrucciones internas, que deben ponerse a disposición de todos los interesados en participar en los procedimientos de adjudicación y publicarse en el perfil de contratante de la entidad ${ }^{119}$.

tienen carácter industrial o mercantil, o bien porque no están controlados o financiados por los poderes públicos. Teniendo en cuenta que los requisitos para ser considerado poder adjudicador son acumulativos, la falta de cualquiera de ellos implicará la inaplicación de las Directivas y, en consecuencia, sus contratos nunca estarán sometidos a regulación armonizada.

117 La LCSP en el artículo 3 apartado $1^{\circ}$ realiza una enumeración exhaustiva de todos los entes del sector público. El apartado 2. ${ }^{\circ}$ especifica los entes que tienen el carácter de Administraciones públicas. Y el 3. recogiendo las previsiones de la Directiva 2004/18/CE incluye las entidades y organismos que tienen la consideración de poderes adjudicadores. De lo que podemos deducir que los entes enumerados en el artículo 3.1 LCSP no considerados Administraciones públicas (artículo 3.2), ni poderes adjudicadores (artículo 3.3), son los denominados por la Ley como otros entes, organismos y entidades del sector público, a los que sujeta de forma mínima a su ámbito de aplicación.

118 Recordemos que la disposición adicional sexta del TRLCAP con el rótulo de «principios de contratación en el sector público», sujetaba la contratación de las sociedades mercantiles de capital mayoritario o exclusivamente público a los principios de publicidad y de concurrencia, salvo que la naturaleza de la operación a realizar sea incompatible con aquéllos.

119 Especifica el artículo 176 LCSP que los entes, organismos y entidades del sector público que no tengan la consideración de poderes adjudicadores deberán ajustarse, en la adjudicación de los contratos, a los principios de publicidad, concurrencia, transparencia, confidencialidad, igualdad y no discriminación. La 
Puesto que la adjudicación de estos contratos no queda sometida a procedimientos determinados y específicos, sino a los principios generales de la contratación, la cuestión a resolver es la relativa a la determinación del alcance de estos principios. Cuestión que pasamos a ver.

\section{BREVE REFERENCIA A LOS PRINCIPOS GENERALES DE CONTRATACIÓN PÚBLICA}

Como señala Moreno Molina los principios generales de la contratación pública, basados en reglas nacionales y comunitarias de naturaleza constitucional (TCE y CE), son el fundamento de la normativa contractual pública y se caracterizan por alcanzar a todas las fases del procedimiento contractual, frente a las Directivas comunitarias que exclusivamente regulan las fases de preparación y adjudicación de los $\operatorname{contratos}^{120}$.

Al margen del importe del contrato, la legislación nacional de contratos públicos debe, en todo caso, respetar los principios ${ }^{121}$ y las normas del TCE ${ }^{122}$, no existiendo ámbitos de contratación pública exentos de su aplicación. Aunque el contrato haya sido celebrado por una entidad instrumental privada (caso de las sociedades mercantiles públicas o de las fundaciones de interés público), no debemos olvidar su conexión directa o indirecta con el interés general, parámetro constitucional donde el sector público debe residenciar sus medidas, actuaciones y decisiones. Este interés general como postulado constitucional ha de predicarse de toda la organización administrativa y no sólo del concepto de Administración pública que contempla la LC$\mathrm{SP}^{123}$. La presencia de ese interés general en la contratación pública se hace visible mediante la realización objetiva de la misma, es decir, incidiendo en que su desarrollo sea imparcial y transparente.

La objetividad en la contratación pública se concreta mediante cauces jurídicos que aseguren la concurrencia entre los distintos agentes económicos, en aplicación

adjudicación de los contratos deberá efectuarse de forma que recaiga en la oferta económicamente más ventajosa. La efectividad de los principios y de la directriz anteriormente enunciados se recogerán en las instrucciones internas de estas entidades que dispondrán lo necesario para asegurarlos.

120 Nos referimos a los principios jurídicos que emanan de la Constitución española y del Tratado CE.

121 En particular, los principios de libre circulación de mercancías, libertad de establecimiento y libre prestación de servicios, así como los principios que se derivan de estas libertades, como el principio de igualdad de trato, no discriminación, reconocimiento mutuo, proporcionalidad y transparencia. Véanse Baño León, J.M. ${ }^{a}$ (2000), «La influencia del Derecho comunitario en la interpretación de la Ley de Contratos de las Administraciones Públicas», Revista de Administración Pública, 151:13; Moreno Molina, J.A. (2006), Los principios generales de la contratación de las Administraciones Públicas, Albacete: Bomarzo; Gimeno Feliu, J.M. ${ }^{a}$ (2003), Contratos públicos: ámbito de aplicación y procedimientos de adjudicación, Madrid: Cívitas.

122 Esta afirmación queda avalada por la Comunicación Interpretativa de la Comisión Europea sobre el Derecho Comunitario aplicable a la adjudicación de contratos no cubiertos, o sólo parcialmente cubiertos, por las Directivas sobre contratación pública, de 1 de agosto de 2006 (2006/C179/02), y reafirmada por la STJCE de 14 de junio de 2007 (asunto Medipac-Karantzidis $A$ )

123 Del Saz Cordero, S. (2008), «La nueva Ley de Contratos del Sector Público... », op., cit., p. 361. 
particularizada del principio constitucional de igualdad, que en este ámbito se manifiesta en la publicidad del contrato y en los procedimientos de selección del contratista. Ahora bien, esta objetividad no deberá medirse sólo por la ejecución de la ley (principio de legalidad), sino en el modo en que dicha ejecución se lleve a cabo, es decir, a través de pautas estereotipadas previamente establecidas y no a través de criterios subjetivos.

Es ilustrativa en este sentido la citada Comunicación Interpretativa de la Comisión Europea de 1 de agosto de 2006, que aunque no es una disposición legislativa, constituye un documento eficaz y útil para celebrar con objetividad la contratación del sector público, y puede servir de excelente guía en la elaboración y aprobación de las instrucciones internas a las que deben someterse los contratos celebrados por los entes del sector público no sujetos a regulación armonizada. Por ello, resaltaremos las pautas fundamentales que marcan la aplicación de los principios generales de la contratación pública:

- Los principios de igualdad de trato y no discriminación comportan la descripción no discriminatoria del objeto del contrato sin hacer referencia a una fabricación o procedencia determinada, ni referirse a una específica marca, tipo, origen o producción, salvo que una referencia de este tipo se justifique por el objeto del contrato, que deberá ir acompañada de la mención «o equivalente». Las entidades adjudicadoras no deberán imponer ninguna condición que suponga una discriminación directa o indirecta a los licitadores, como, por ejemplo, la obligación de que las empresas interesadas en el contrato estén establecidas en el territorio del mismo Estado miembro o de la misma región que la entidad adjudicadora. Y tendrán prohibido facilitar de forma discriminatoria información que pueda proporcionar ventajas a determinados licitadores respecto del resto. El número de candidatos invitados puede limitarse siempre que dicha limitación se encuentre justificada y se efectúe de forma transparente y no discriminatoria ${ }^{124}$. Por último, quedan sujetas al reconocimiento mutuo de títulos, certificados y otros diplomas.

- El principio de transparencia implica: que todos los participantes deben conocer previamente las normas aplicables al contrato, así como tener la certeza de que dichas normas se aplicarán de igual forma para todas las empresas. Las negociaciones deberán organizarse de modo que todos los licitadores tengan acceso a la misma información. La adjudicación deberá ajustarse a las normas y requisitos establecidos inicialmente ${ }^{125}$. Se deberán fijar plazos adecuados para permitir a las empresas realizar una evaluación y formular sus

124 A tal efecto podrían utilizarse criterios como la exigencia de determinada experiencia, el tamaño e infraestructura de las empresas candidatas, los conocimientos técnicos y otros análogos. Podrá optarse también por un sorteo, bien como mecanismo de selección o como combinación de ambos.

125 Previa selección bajo los principios de no discriminación y de transparencia, podrán las entidades adjudicadoras confeccionar una lista de operadores cualificados, para celebrar contratos a partir de dicha lista y sobre una base de un trato igualitario, ejemplo, por turno rotatorio dentro de la lista. 
ofertas, y precisar previamente los criterios objetivos aplicables para la valoración de las ofertas. En este sentido el TJCE ha declarado que no pueden tenerse en cuenta como criterios de adjudicación las características o experiencia de la empresa o el nivel y características de los medios que deban emplearse para la ejecución del contrato, que sólo se valorarán como elementos de solvencia. La adjudicación del contrato se hará a favor de la oferta económicamente más ventajosa de acuerdo con los objetivos de valoración de las ofertas que en cada caso se hayan establecido.

- En cuanto al principio de publicidad, la Comisión Europea recomienda que se garantice una publicidad ${ }^{126}$ que permita abrir a la competencia la contratación pública y controlar la imparcialidad de los procedimientos de adjudicación ${ }^{127}$. Sugiriendo que la publicidad no debe implicar necesariamente una convocatoria formal del contrato y por tanto el anuncio puede limitarse a una breve descripción de sus detalles esenciales, la forma de adjudicación y los datos para tomar contacto, en su caso, con la entidad adjudicadora ${ }^{128}$. Puesto que para los contratos celebrados por entidades que no ostentan la condición de poderes adjudicadores la LCSP no establece ninguna previsión sobre los medios de publicidad, salvo la remisión al perfil de contratante, cabe entender que su determinación queda remitida a la entidad contratante que deberá utilizar un medio adecuado. Será, por tanto, la propia entidad la que decida la forma más adecuada de dar efectividad al principio de publicidad, sin que para ello sea necesario, aunque sí posible acudir a las normas concretas de la LCSP.

- Principio de confidencialidad, la concreción de este principio queda recogida en el artículo 124 LCSP en una doble vertiente, confidencialidad del órgano de contratación y confidencialidad del contratista. Para el órgano de contratación el apartado $1 .^{\circ}$ de dicho precepto determina que sin perjuicio de la información que debe facilitar a los candidatos y licitadores, no podrá divulgar la información que los empresarios hayan designado como confidencial; este carácter afecta, en particular, a los secretos técnicos o comerciales y a los aspectos confidenciales de las ofertas. Para el contratista el apartado $2 .^{\circ}$ del artículo 124 LCSP dispone que deberá respetar el carácter confidencial de

126 Sin predeterminar la forma de publicidad que será responsabilidad de las entidades adjudicadoras, la Comunicación de la Comisión Europea señala como formas de publicidad adecuadas: Internet, boletines oficiales y especializados, diarios locales cuando se trate de contratos de muy escasa cuantía, únicamente destinados al mercado local, DOUE, y el Diario electrónico de licitaciones. Creo que en España este último medio tendrá correspondencia con la Plataforma de Contratación del Estado a que se refiere el artículo 309 de la LCSP.

127 Véase la STJCE de 13 de octubre de 2005, Asunto C-458/03 y los artículos 43 y 49 TCE.

128 La STJCE de 21 de julio de 2005, Asunto C-321/03, declara que corresponde al órgano jurisdiccional remitente verificar si la adjudicación cumple el requisito de transparencia, el cual, sin imponer necesariamente la convocatoria de una licitación, permite, en particular, que una empresa establecida en otro Estado miembro que no sea la República Italiana pueda tener acceso a una información adecuada sobre dicha concesión antes de su adjudicación, de forma que, de haberlo deseado, esté en condiciones de ma76 nifestar su interés por obtener dicha concesión (apartado 21 de la citada Sentencia). 
aquella información a la que tenga acceso con ocasión de la ejecución del contrato a la que se le hubiese dado el referido carácter en los pliegos o en el contrato, o que por su propia naturaleza deba ser tratada como tal.

- Por último, en cuanto a la protección judicial'29, la Comisión recomienda una protección judicial efectiva de los derechos de los ciudadanos, siendo el Derecho nacional el que debe regular los procedimientos de impugnación ${ }^{130}$. Y estos procedimientos no serán menos eficaces que los aplicables a reclamaciones similares, en virtud del principio de equivalencia, ni imposibilitar o dificultar excesivamente la protección judicial, conforme al principio de eficacia $^{131}$. Las entidades adjudicadoras darán a conocer los motivos de las decisiones que pueden recurrirse, bien en la propia decisión o previa petición de los interesados, tras la comunicación de la adjudicación ${ }^{132}$.

129 Las impugnaciones que se susciten en los actos de preparación, adjudicación, efectos y extinción de los contratos celebrados por entidades que no ostentan la condición de poderes adjudicadores, al tratarse de contratos privados no sujetos a regulación armonizada, han de residenciarse en el orden jurisdiccional civil mediante la interposición de la correspondiente demanda.

130 La STJCE de 25 de julio de 2002, Asunto C-50/00, declara que los particulares deben disfrutar de una tutela judicial efectiva de los derechos que les confiere el ordenamiento jurídico comunitario, ya que el derecho a dicha tutela forma parte de los principios generales del Derecho que resultan de las tradiciones constitucionales comunes de los Estados miembros.

131 De forma reiterada el TJCE viene declarando que debe analizarse en cada caso si una disposición procesal nacional imposibilita o dificulta excesivamente la aplicación del Derecho comunitario, teniendo en cuenta el lugar que ocupa dicha disposición dentro del conjunto del procedimiento, de su desarrollo y de sus peculiaridades (STJCE de 27 de febrero de 2003, Asunto C-327/00).

132 La STJCE de 15 de octubre de 1987, Asunto 222/1986, especifica que la eficacia del control jurisdiccional, que debe abarcar la legalidad de los motivos de la decisión impugnada, implica, de manera general, que el juez al que se recurre pueda exigir de la autoridad competente la comunicación de estos motivos. 
